\title{
Freely-propagating flames in aluminum dust clouds
}

\author{
Philippe Julien, James Vickery, Samuel Goroshin, David Frost, Jeffrey Bergthorson \\ McGill University, Department of Mechanical Engineering \\ 817 Sherbrooke West, H3A 0C3, Montréal, Québec, Canada
}

Corresponding author: Philippe Julien, philippe.julien@mail.mcgill.ca

Full-length paper

\begin{abstract}
The free propagation of isobaric flames through aluminum dust clouds is investigated in an extensive series of experiments using two facilities with different scales. In small-scale laboratory experiments, spherical flame propagation occurs in aluminum dust clouds contained within 30-cm-diameter latex balloons, whereas in large-scale tests, flames propagate vertically through unconfined aluminum dust clouds with a vertical scale of about $4 \mathrm{~m}$. The balloon experiments are performed with suspensions of aluminum powder in oxygen mixed with nitrogen, argon, or helium with various concentrations of oxygen and aluminum. It is found that stable flame propagation is only observed for aluminum concentrations near stoichiometric to rich conditions. Pulsating and spiral-like flames are discovered in fuel-lean mixtures, and flames with cellular patterns occur in very-fuel-rich suspensions. The burning velocities in the stable propagation regime derived from the balloon experiments correlate well with data previously obtained with stabilized Bunsen-type flames. The flame speed of stable flames is found to be a strong function of the heat conductivity of the gas mixture. In addition, the oxygen concentration has a strong influence on the flame speed for fuel-rich mixtures but dependence is reduced for fuel-lean mixtures. In the large-scale experiments, the burning velocity is estimated to be about two times larger than for the small-scale experiments. The increase in burning velocity is attributed to preheating of the unburned mixture by radiation from the condensed-phase combustion products. The degree of preheating, determined with an array of fine thermocouples, is found to be in the range of $150-200 \mathrm{~K}$. The propagation of stable flames is discussed in light of existing qualitative dust flame models, whereas the pulsating flame propagation regime observed is interpreted in terms of the thermo-diffusive instability theory developed for high Lewis number flames in gases and solid reactive powder mixtures.
\end{abstract}

Keywords: aluminum flame; pulsating flame; radiation heat transfer; freely-propagating flame; burning velocity 


\section{Introduction}

Suspensions of combustible particles in an oxidizing media are ubiquitous in industry, agriculture, transportation and propulsion technology [1]-[6]. Though often amalgamated together under the term "combustible dusts", solid fuels are very diverse, ranging from very volatile organic substances, such as plastics, flour, sugar or cornstarch, to refractory materials, such as carbon (graphite) or iron that do not volatilize or evaporate. Organic dusts have melting and volatilization temperatures well below their flame temperature, such that their combustion behavior differs little from the combustion of hydrocarbon droplets. The evaporation or decomposition of the organic volatile fuel and hydrocarbon sprays in the flame preheat zone might lead to the formation of a continuous flame sheet in the case of small particles and large fuel concentrations or, for large particles in fuel-lean mixtures, result in the combustion of particles surrounded by individual diffusion micro-flames [7]. Complex fuels, such as coal, contain both volatile and refractory substances and burn partially in the vapor phase by volatilization while leaving a charred core that burns heterogeneously.

Irrespective of the boiling temperature of the metal, the extremely fast and non-activated reaction kinetics of metal vapors with oxygen precludes formation of a premixed metal-vapor mixture in the flame preheat zone. [8], [9]. This excludes complex mixed heterogeneous/homogeneous flame regimes typical for combustion of solid and liquid hydrocarbon fuel suspensions which, combined with the fact that metals are pure elemental substances with well-defined properties, available in a wide range of particle sizes, makes flames in metal suspensions well-suited for the academic study of heterogeneous dust flames. Among all metals, aluminum is of special interest since it is often used as an energetic additive to propellants, explosives and pyrotechnics.

In contrast to hydrocarbon flames, the field of dust combustion remains vastly underdeveloped. This is partly due to the experimental difficulty of obtaining a laminar suspension of solid particles which is required to measure the fundamental combustion parameters, such as the burning velocity. Dust particles rapidly settle in a quiescent environment, and, in order to maintain the dust in suspension, an ascending laminar flow or some level of flow turbulence is required. For large particles that are tens of microns or more in size, the flow velocity that is required to counteract particle settling may even exceed the flame burning velocity. Thus, performing dust combustion experiments over a wide range of particle sizes ultimately requires a microgravity environment [10]. Furthermore, the combustion behavior of a dust suspension depends on the particle morphology and size distribution, which makes it difficult to compare experimental data obtained from different research groups using dissimilar powders. Due to the large flame thicknesses and the possibility of heat transfer from the flame to the fresh unburned mixture by radiation, dust flames are also more sensitive to the system scale than gaseous flames. 
The vast body of literature on dust combustion is mostly based on experiments in closed bombs with no visual access, where the pressure history within the vessel is the only parameter measured. This experimental technique is primarily used to empirically classify the explosivity of dusts based on the rate of pressure rise, in accordance with the explosion hazard scale, while leaving the scientific questions of the flame structure and flame propagation mechanism unresolved. Only a small number of experimental groups, using different techniques, have provided direct measurements of the flame propagation speeds from which the burning velocity can be extracted. For example, Cassel employed stabilized Bunsen-type flames [11], Ballal et al. [12] performed experiments with flat flames in a tube in microgravity, and Sun et al. [13]-[15] explored freely-propagating flames at very small scales. For the past 20 years, researchers at McGill University have systematically used visual observation of metal dust and hybrid hydrocarbon/metal-dust flames stabilized on Bunsen burners [16]-[19], propagating in tubes in normal and microgravity environments [20]-[23], and, more recently, spherically expanding in transparent latex balloons [24], to determine flame speeds and flame structure. The systematic use of the same batch of aluminum powder in the different experiments has facilitated the accumulation of a unique dataset of aluminum dust flame properties such as burning velocity, flame quenching distance, and flame spectral characteristics. This comprehensive compendium of data allows for the direct comparison of properties using different methods to fully characterize the combustion properties and flame structure.

As a continuation of this systematic work, the present study introduces two new experimental facilities allowing the observation of freely-propagating dust flames with different scales [24]. The first laboratory-scale apparatus uses transparent latex balloons to observe nearlyconstant-pressure spherically-expanding flames up to $30 \mathrm{~cm}$ in diameter [25]. The aluminum is suspended within the balloon by a pulsed dispersal system in different gaseous mixtures of oxygen with nitrogen, argon or helium. Special care is taken to minimize the influence of the residual turbulence induced by the dust dispersal process by introducing an ignition delay time of appropriate length. The second apparatus creates aluminum dust clouds that are about $2 \mathrm{~m}$ wide and $4 \mathrm{~m}$ high inside a large-scale indoor experimental fire tower. The flame is initiated at the bottom of the cloud with a pyrotechnic igniter. A grid of thermocouples of different sizes placed inside the dust cloud is used to measure the level of long-range preheating of the dust mixture through the radiative flux ahead of the flame. The burning velocity results from the laboratory and larger scale experiments are compared with the data previously obtained from stabilized Bunsen-type dust flames [16]. Pulsating and spiral instabilities in spherical aluminum flames are discovered in fuel-lean mixtures and are discussed in reference to the general thermo-diffusive theory of flame stability developed for gaseous flames and condensed systems [26]-[28]. 


\section{Experimental Methods}

\subsection{Small-scale flames in balloons}

The transparent latex balloons have a diameter of about $30 \mathrm{~cm}$ and volume of about $14 \mathrm{~L}$ when inflated prior to injection of the powder (Fig. 1). As the flame propagates, the balloon expands, maintaining essentially isobaric conditions up until it bursts with a pressure rise that is less than 0.01 bar. The aluminum powder is initially placed in a hemispherical cup at the bottom of a cylindrical dispersion unit that has a maximum capacity of $8 \mathrm{~g}$ of powder. The powder is fluidized within the cylindrical chamber by an impinging pulse of high-pressure gas. The particles become entrained in the flow, and the aluminum-gas mixture travels upward through a hemispherical cap before entering the pre-inflated balloon. The cap is pierced with multiple holes to separate the two-phase flow into many particle-laden jets that move up through the center of the balloon. The suspended particles recirculate within the balloon, mixing with the gas mixture until a uniform gas-particle mixture is created within the balloon, as shown in Fig. 2. The powder suspension is then centrally ignited by a heated tungsten wire following a $4 \mathrm{~s}$ delay after the initial powder injection to allow the initial turbulence to decay, as described in a previous publication [24]. The dust dispersal and flame propagation processes are recorded using a highspeed Photron SA5 videocamera, operated at 4,000-7,500 frames per second. Neutral density filters are used to attenuate the light intensity of the intensely luminous flames at high dust concentrations. A photodiode and a microphone, installed near the balloon and synchronized with the camera, monitor the history of the flame brightness and the acoustic waves emitted by the flame, respectively. More details on the design and operation of the apparatus are given in a previous publication [24]. 


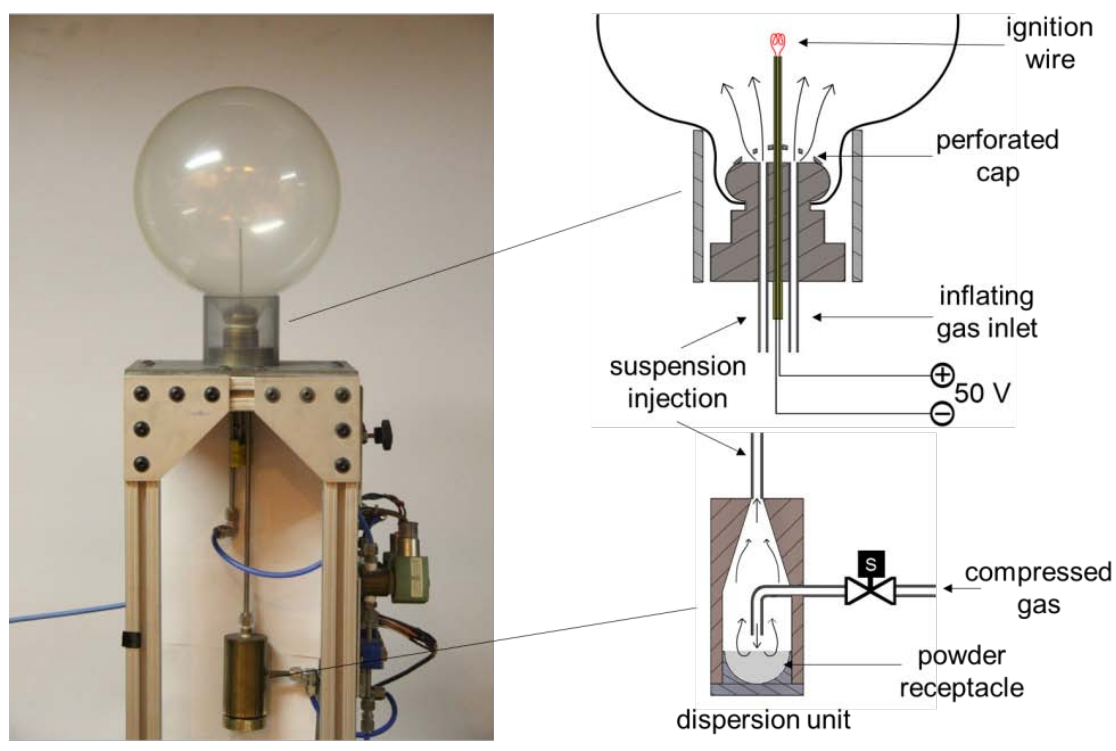

Figure 1. Schematics and photograph of the laboratory apparatus for observation of spherical dust flames in transparent latex balloons.

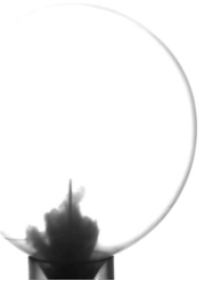

$0.1 \mathrm{~s}$

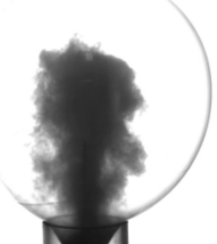

$0.4 \mathrm{~s}$

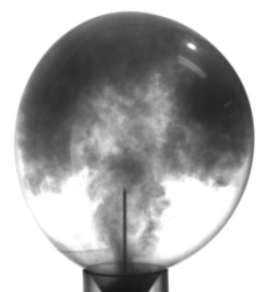

$0.7 \mathrm{~s}$

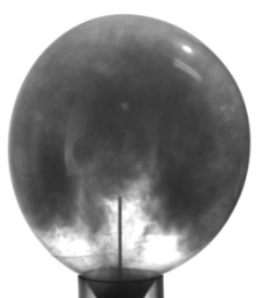

$1.0 \mathrm{~s}$

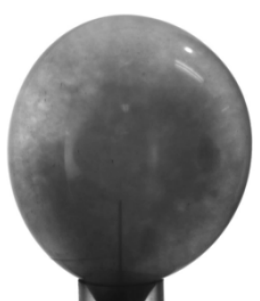

$1.3 \mathrm{~s}$

Figure 2. Still frames of the dispersion of $\mathbf{4 g}$ of aluminum powder in the latex balloon apparatus for a final concentration of approximately $200 \mathrm{~g} / \mathrm{m}^{3}$.

In most dust combustion experiments within closed vessels, it is usually assumed that the dust is uniformly dispersed throughout the vessel volume without any powder deposition, and hence the dust concentration is calculated by simply dividing the mass of the dust sample by the inner volume of the vessel. However, some portion of the powder does not remain in suspension but, rather, accumulates on the vessel wall or settles to the bottom of the chamber prior to ignition. In the present experiment, some degree of powder deposition also occurs, and hence a calibration is performed to correlate the mass of the dust sample initially within the dispersion unit with the actual amount of dust in suspension at the moment of ignition. A rigid acrylic sphere with a similar size and volume is used in place of the latex balloons in conjunction with a laser light-attenuation probe to calibrate the dust concentration [16]-[19]. The probe consists of a 
$633 \mathrm{~nm}$ red laser and a photodiode with a narrow-bandpass filter corresponding to the wavelength of the laser. The powder is dispersed as usual but not ignited. The powder concentration is derived from the photodiode output signal using the Beer-Lambert law, which states that the logarithm of the light attenuation corresponds to the powder concentration multiplied by a constant. This constant, which depends on the distance traveled by the laser and the type of powder used, has been determined in previous experiments using the same powder [18], [19]. Figure 3 shows a typical time history of the dust concentration determined within the suspension during and after the dust dispersal process.

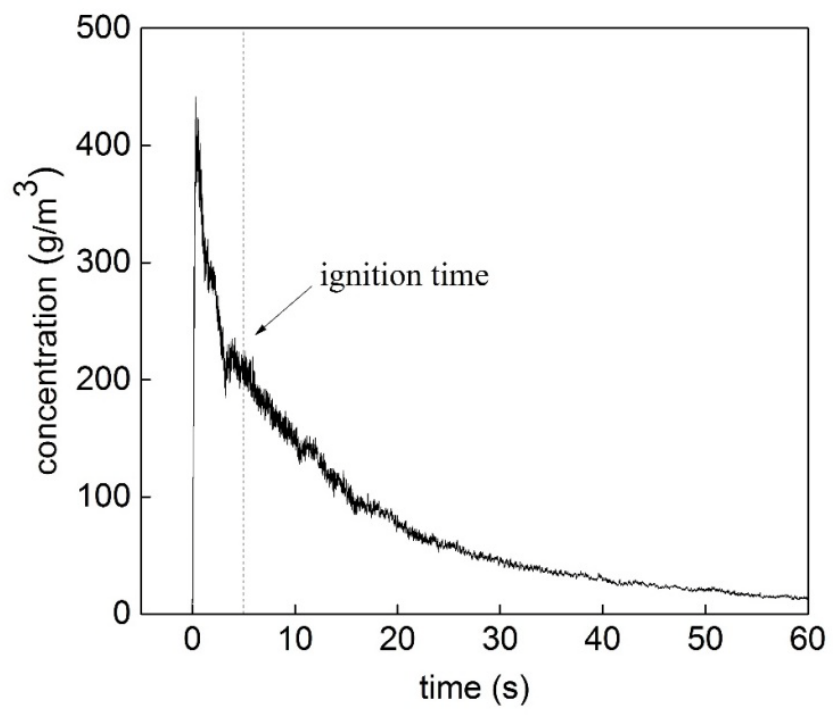

Figure 3. Time history of the aluminum dust concentration in the balloon measured by the laser light attenuation probe. 


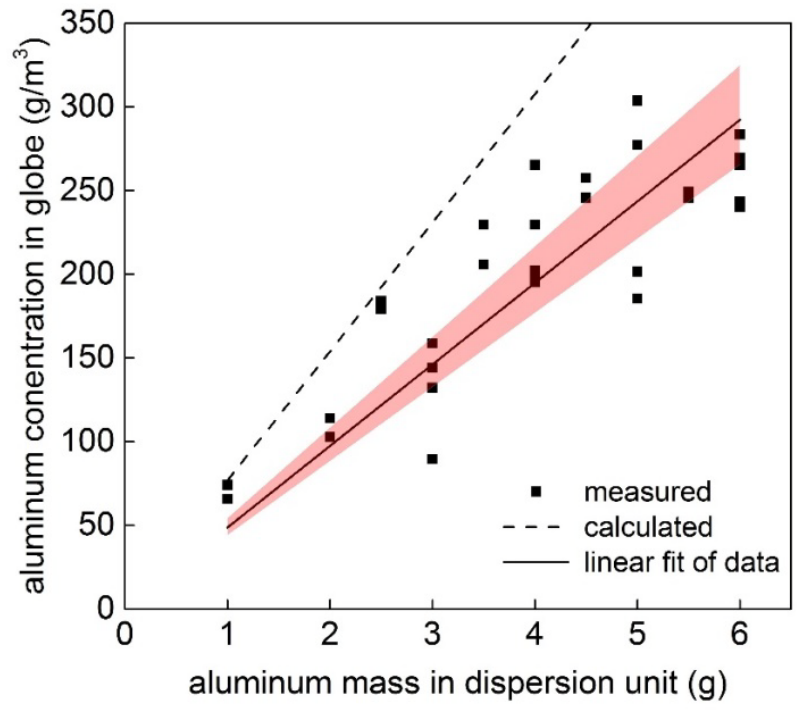

Figure 4. Experimentally measured concentration of the aluminum in suspension at the moment of ignition (4 $s$ after the start of dispersion) as a function of the amount of aluminum dust initially placed in the dispersion unit. The shaded area represents the $\mathbf{9 5 \%}$ confidence interval of the fit,the solid line the least-square fit and the dashed line is the estimate of the aluminum concentration obtained assuming that the entire dust sample remains in suspension.

As can be seen from the concentration measurements and high-speed photographic records of the dispersal process (see Fig. 2), the probe initially records a very high dust concentration as the multiphase flow jets move through the center of the balloon where the probe is positioned. The ascending multiphase flow then impinges on the balloon wall and is deflected outwards and downwards near the balloon wall. The large-scale vortical motion that is induced cascades down to smaller-scale turbulent eddies that uniformly distribute the dust throughout the balloon volume. The dust concentration continues to decline following dispersion due to powder settling. The graph in Fig. 4 shows the result of dust concentration measurements at the moment of cloud ignition, which is set at a delay time of 4 seconds, as a function of the amount of aluminum dust placed within the dispersion receptacle. As can be seen, the measured concentration correlates with, but is considerably below, the calculated values assuming all the dust remains in suspension at the moment of ignition. The difference increases with the weight of the dust sample and reaches almost a factor of two for large masses of powder.

\subsection{Large-scale unconfined flames}

Combustion experiments in large-scale aluminum dust clouds are performed using the dust dispersal device previously developed [24] and shown in Fig. 5 below. The apparatus is essentially a scaled-up version of the dust dispersal unit used with our laboratory Bunsen burner, as described by Soo et al. [19] and Julien et al. [18], and can create a large uniform column of suspended powder. Up to $1 \mathrm{~kg}$ of aluminum powder is initially loaded into the cylindrical cartridge having an inner diameter of about $5 \mathrm{~cm}$ and length of $30 \mathrm{~cm}$. During the dispersal 
process, the powder column is displaced upwards at constant speed by a pneumatic piston and is progressively de-agglomerated and entrained into the vertical air flow generated by an impinging sonic annular air jet (or air-knife) at the top of the cartridge. All of the powder within the cartridge is dispersed within a time of less than 1 second, as shown in Fig. 6, creating a vertical dust cloud about $4 \mathrm{~m}$ tall and $2 \mathrm{~m}$ wide near the top.

Initial tests were performed at an outdoor test site [24], but it was necessary to initiate the flame propagation promptly during the latter stages of the dispersal process to avoid the displacement of the dust cloud by the ambient wind conditions. To provide a sufficient delay time between powder dispersal and ignition to allow the turbulence within the multiphase cloud to decay, quiescent ambient conditions are required. Hence, the present experiments were performed indoors in the large-scale fire tower at the Fire Research Laboratory of the National Research Council of Canada (Mississippi Mills, Ontario, Canada). The tower is approximately 10 stories $(35 \mathrm{~m})$ high and has about $200 \mathrm{~m}^{2}$ of floor area. Two large, variable-area openings at the tower base allow the intake of outside air for ventilation and prevent any pressure build up during the flame propagation. The combustion products are vented through openings in the ceiling connected to a powerful ventilation system, which is operated only after the combustion event is completed to avoid disturbing the cloud formation and flame propagation.

Cloud ignition is achieved with a small $2 \mathrm{~g}$ charge of black powder placed at the cloud base, which is initiated by an electrically-heated bridge wire. The ignition charge is placed on a mast to vary the height as the ignition delay times are adjusted. Another mast with two rows of bare junction K-type thermocouples with three different bead sizes $(0.075,0.0125$ and $0.25 \mathrm{~mm})$ is placed close to the dispersal unit, with the thermocouple arms extending into the dust cloud axis to record the temperature history within the cloud during the passage of the flame. A Photron SA5 videocamera was used to record the flame propagation at 2,000 frames per second. The camera record and temperature measurements were synchronized using a photodiode signal from the ignition event. 


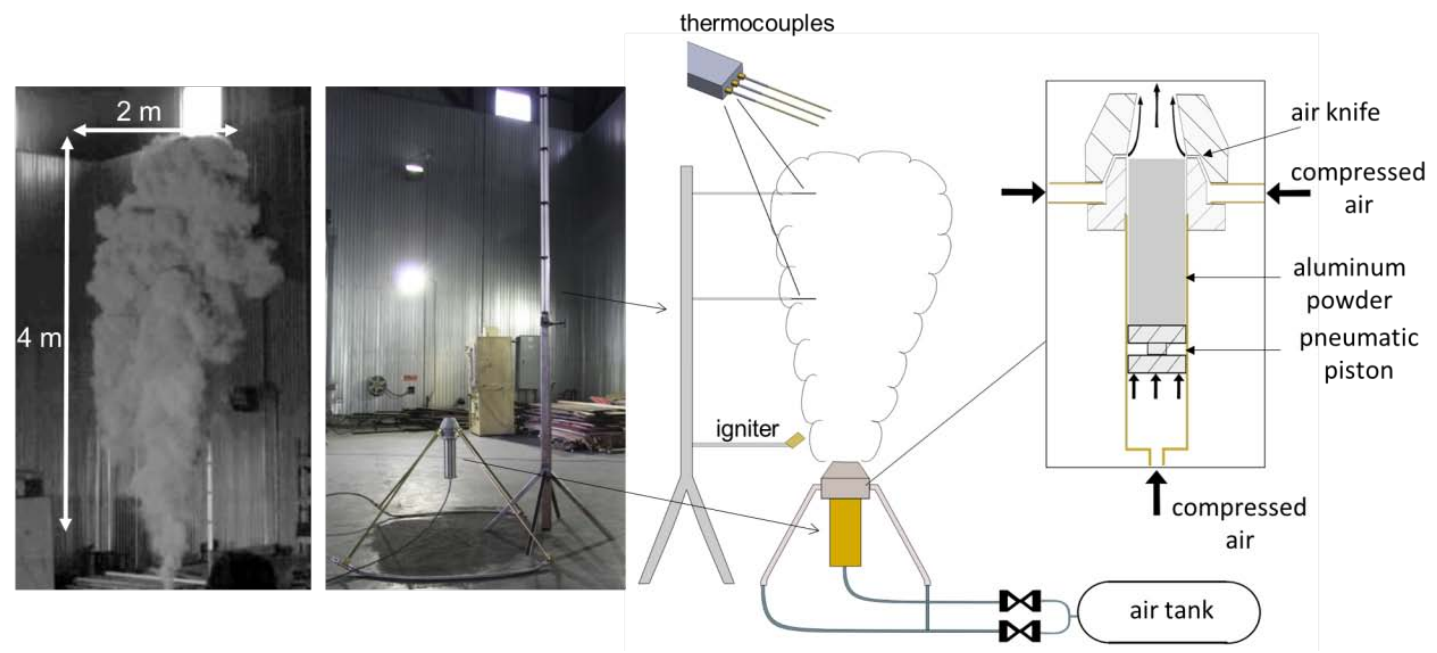

Figure 5. Schematics and photograph of the experimental rig for the large-scale dust cloud combustion tests.

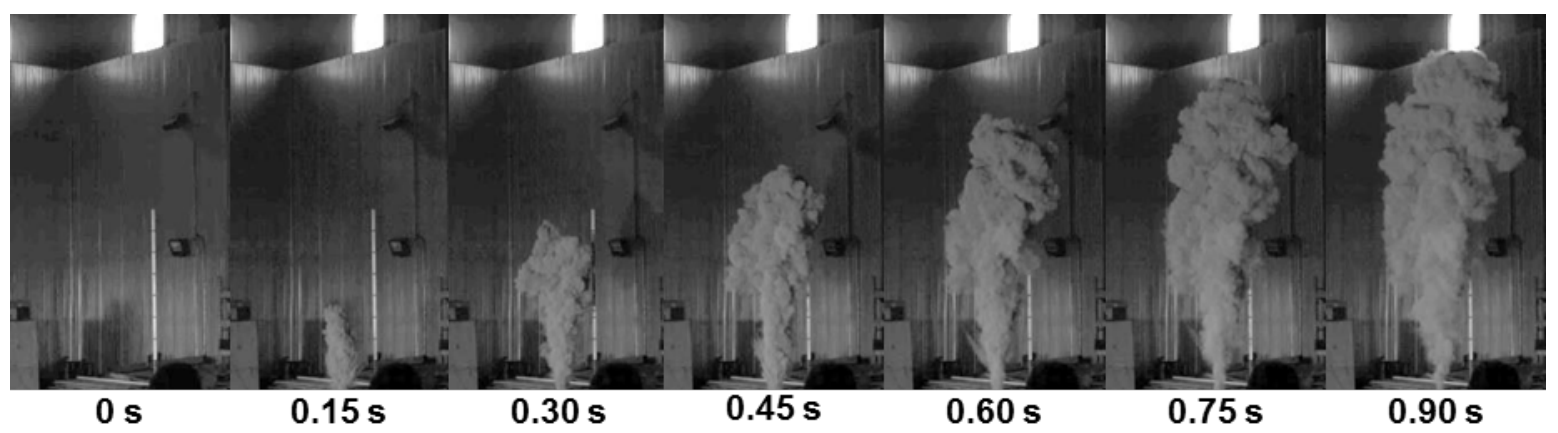

Figure 6. Still frames of dust dispersion process for large-scale tests.

\subsection{Aluminum powders and gaseous mixtures}

Three different types of aluminum powders were used in the present investigation. The laboratory experiments in latex balloons were performed with Ampal 637 (Ampal Inc., NJ) aluminum powder that is comprised of nodular-shaped particles, as shown in the SEM image in Fig. 7. The large-scale experiments were performed using either $\mathrm{H}-5$ or $\mathrm{H}-10$ aluminum powder manufactured by Valimet Inc. (Stockton, CA), which have a relatively spherical morphology as shown in Fig. 7. The large-scale experiments required large quantities of powders, such that the amount of Ampal 637 available was insufficient. The particle size distributions of Valimet H-5 and H-10 powders were obtained using a Malvern Mastersizer 2000 are shown in Fig. 7, and have considerable overlap with the particle size distribution of Ampal 637 powder.

The various test series within the balloons were performed with oxygen concentrations ranging from $15 \%$ to $100 \%$. The oxygen is diluted with nitrogen, argon or helium to have 
different heat capacities and diffusivities while keeping the concentration of aluminum and oxygen constant. Oxidizing mixtures are prepared in a mixing tank by partial pressure.

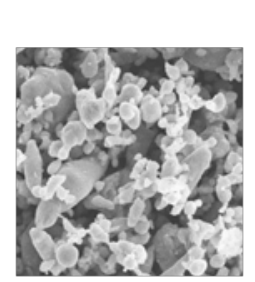

Ampal

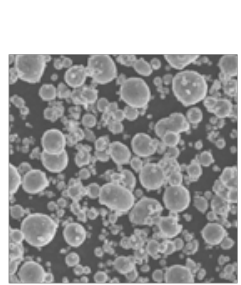

H5

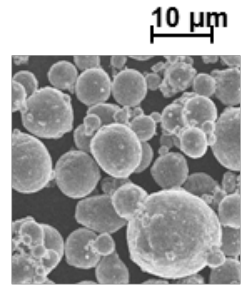

H10

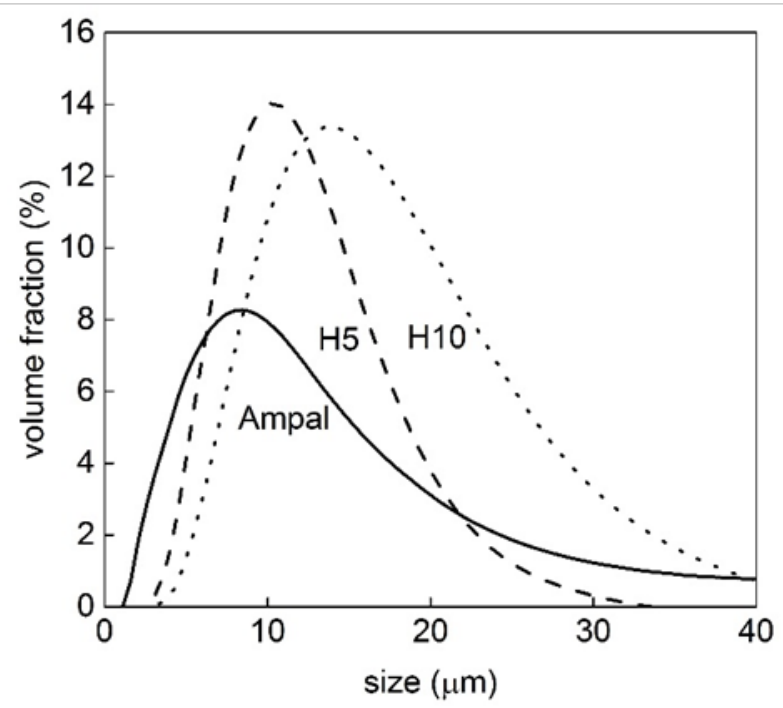

Figure 7. Electron microscope photographs and particle size distributions of Ample 637 and Valimet $\mathrm{H5}$ and H10 aluminum powders.

\section{Results}

\subsection{Spherically-expanding flames in balloons}

\subsubsection{Regimes of flame propagation}

Different regimes of flame propagation are observed in the present experiments, and the type of regime depends primarily on the fuel equivalence ratio, i.e., on the oxygen and aluminum concentrations. Mixtures in the vicinity of stoichiometric concentrations exhibit stable propagation of a smooth flame expanding radially outwards after central ignition. Figure 8 shows still frames from a stable flame experiment, with an aluminum concentration of about $370 \mathrm{~g} / \mathrm{m}^{3}$ in air. 


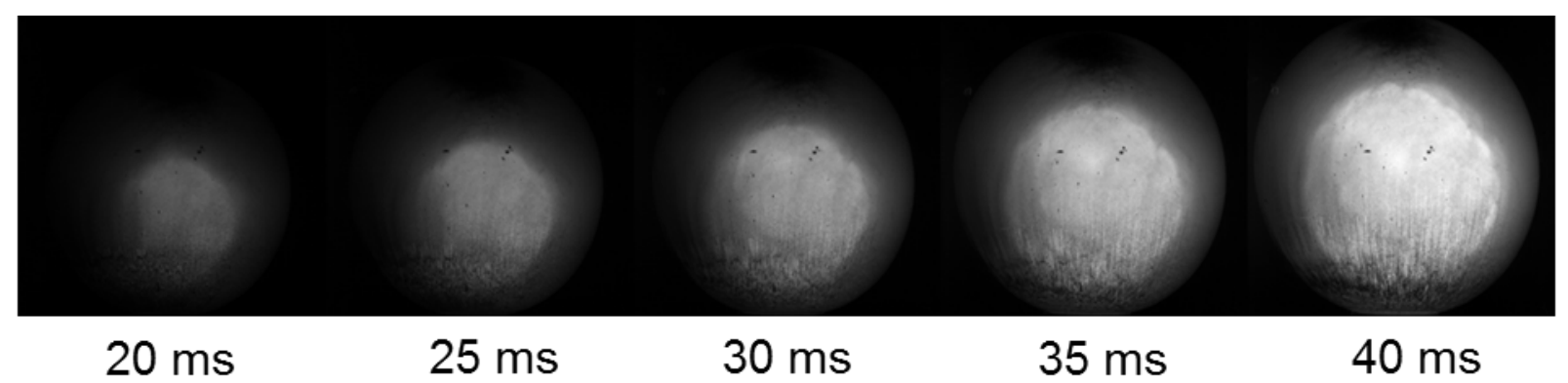

Figure 8. Flame front propagation in near-stoichiometric suspension in air at aluminum dust concentration of about $370 \mathrm{~g} / \mathrm{m}^{3}$. Stoichiometric concentration of aluminum in air is about $320 \mathrm{~g} / \mathrm{m}^{3}$.

Several unstable combustion regimes were observed in both very fuel-rich mixtures and fuel-lean mixtures. On the rich side, flames have exhibited cellular patterns on their surface. In fuel-lean suspensions, the flame instabilities are classified into the following four categories, listed in order of decreasing aluminum concentration starting from stoichiometric conditions: i) decaying pulsating flames (pulsations with diminishing amplitude), ii) regular pulsating flames (pulsations with constant amplitude), iii) pulsating flames accompanied by spiral patterns formed on the flame surface, and iv) spiral flames.

Flames with decaying pulsations, followed immediately by pulsations, are the first forms of instabilities that are observed as the concentration of aluminum is decreased below the stoichiometric value. The first regime is referred to as "decaying pulsations" on the graph of Fig. 10 below. In both cases, pulsations start immediately after ignition and are characterized by brief periods of intense luminosity followed by an apparent extinguishing of the flame where the brightness of the flame is reduced by almost an order of magnitude. At aluminum concentrations only slightly below the stoichiometric value, the pulsations are weak, and the flame often starts to propagate steadily after only a few pulsating periods. As the aluminum concentration is decreased still further, the pulsations become more intense and persist until the flame reaches the balloon wall. Figure 9 shows still frames from two periods of such a pulsating flame. 

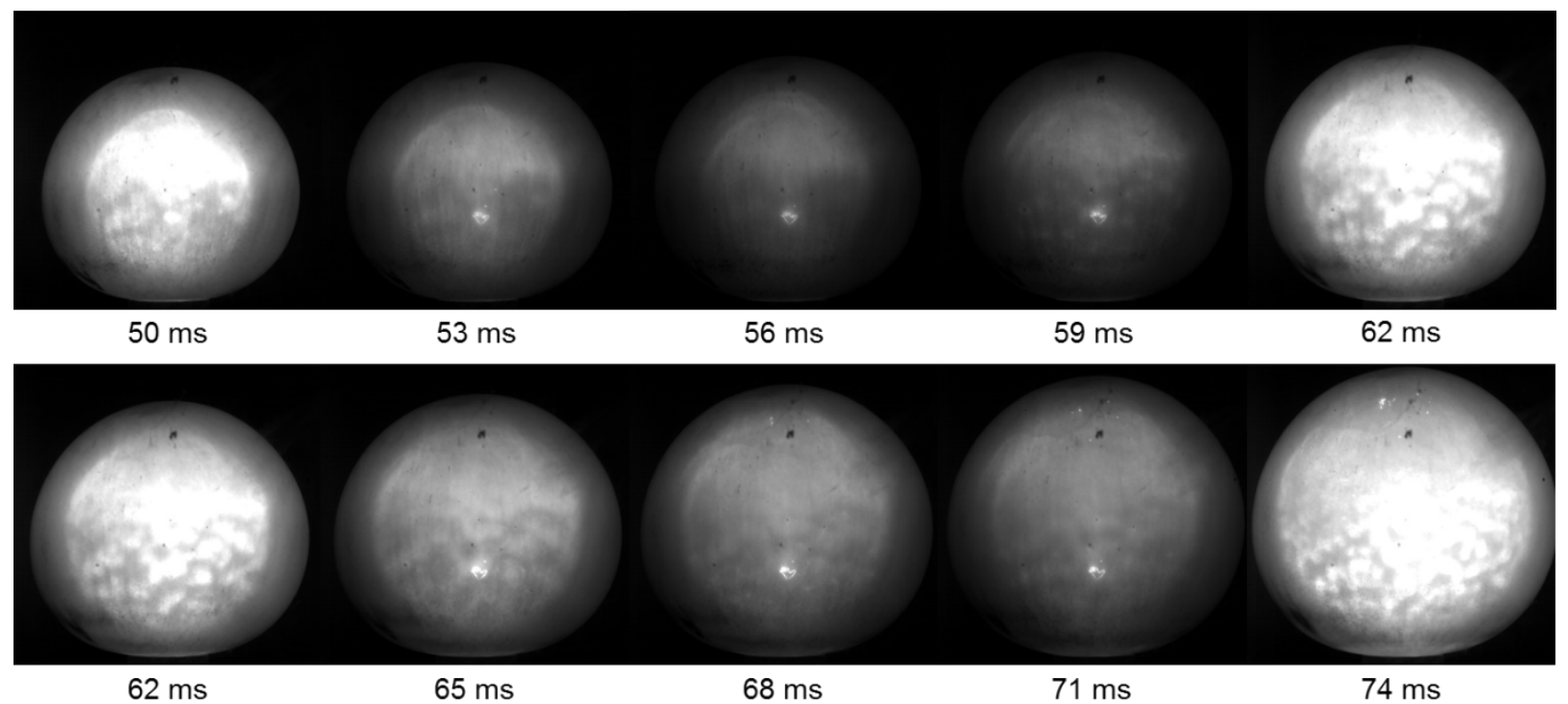

Figure 9. Still frames illustrating two periods of a pulsating aluminum flame in lean aluminum suspension in $60 \% \mathrm{O}_{2} / 40 \%$ Ar gas mixture and aluminum concentration of about $280 \mathrm{~g} / \mathrm{m}^{3}$.

At very low aluminum concentrations, near the lean flammability limit, a second type of thermo-diffusive instability is observed. Spiral waves, often referred to in the literature as spin combustion, can be clearly observed on the flame front. For extremely lean mixtures, when the flame speed becomes comparable to, or lower than, the flow speed induced by the buoyancy of the hot combustion products, the flame propagates upwards in the form of rotating spirals. The spirals appear to start and stop at different locations, and multiple rotating spirals can be observed simultaneously. A spiral flame is shown in a video in supplementary materials. When the mixture has an aluminum concentration between the values associated with the pulsation and spiral regimes, a combination of these two types of instabilities can be observed simultaneously. The flame pulsates, with the clear formation of spiral patterns on the flame surface during the burning phase.

Figure 10 presents the mapping of the different combustion regimes as a function of aluminum and oxygen concentrations in gaseous mixtures of oxygen with helium, nitrogen or argon. The horizontal dashed lines crossing the different columns indicate stoichiometric aluminum concentrations for each specific oxygen concentration. The present experimental setup allows for a maximum aluminum concentration of about $550 \mathrm{~g} / \mathrm{m}^{3}$, such that fuel-rich conditions are only possible in mixtures with oxygen concentration below $30 \%$. As can be seen from Fig. 10, most fuel-rich mixtures, as well as fuel-lean mixtures with fuel equivalence ratios above 0.8 , exhibit stable flame propagation. As the aluminum concentration is lowered below this value, the flame generally first starts propagating with decaying pulsations. As the concentration is decreased the pulsations grow stronger and persist until the flame front reaches the balloon wall. As the dust concentration is reduced even further, pulsations are followed by pulsations with spirals and, finally, purely spiral flames. It is interesting to note that spiral flames 
occur more frequently in nitrogen-oxygen mixtures while the combination of spirals and pulsations occurs more frequently in helium-oxygen mixtures.

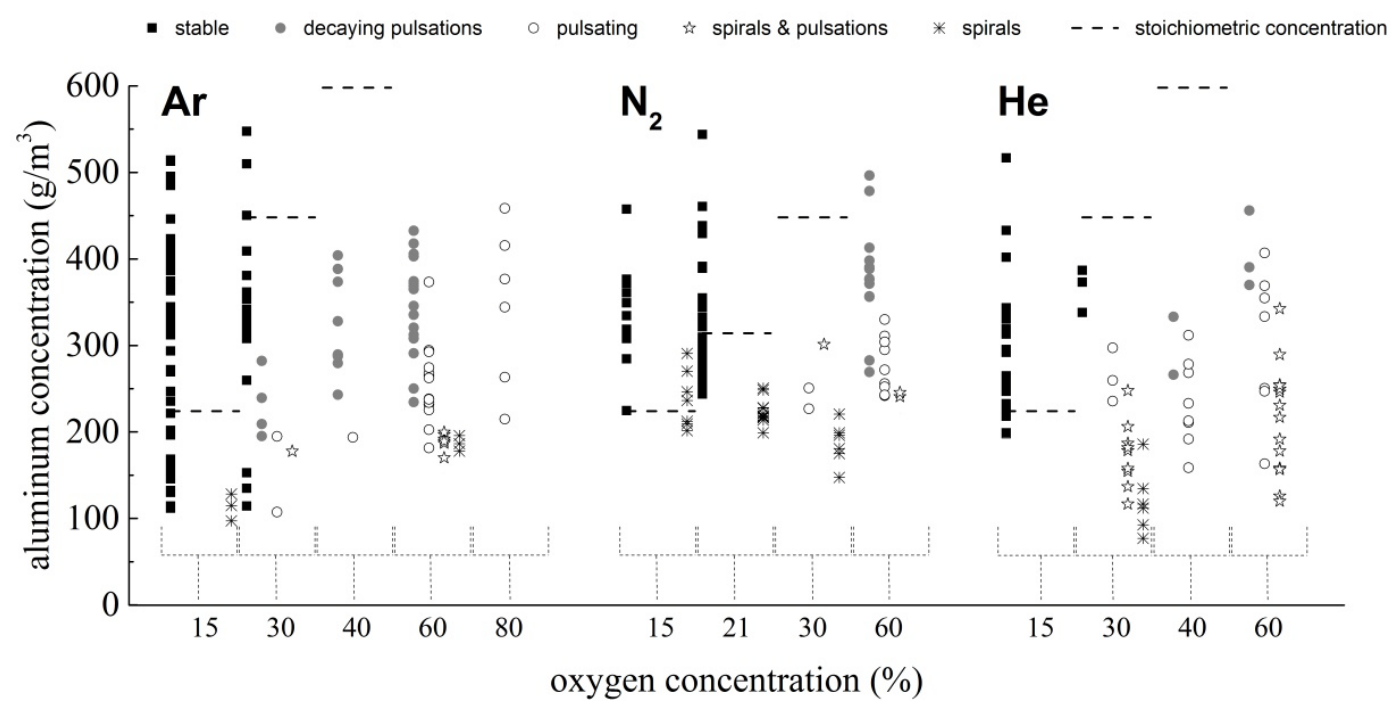

Figure 10. Map of the different regimes of combustion observed for variable oxygen and aluminum concentrations for several inert diluents.

\subsubsection{Propagation speed of stable flames}

The propagation speed of stable flames is determined from the high-speed video records. As the flame is not always spherically symmetrical, the contour of the flame front on each frame was fit with an ellipse. The mean flame radius is then defined as the average distance from the edge of the ellipse to its center-of-mass. The flame radius is plotted as a function of time and a leastsquares fit to the data is used to find the slope of the line giving the flame speed, $S_{f}=\frac{d r}{d t}$ [24]. The experimental data points of flame speed in air in the stable flame propagation regime are shown in Fig. 11 for different mass concentrations of aluminum in suspension. As can be seen from Fig. 11, in fuel-lean mixtures, which corresponds to the portion of the curve left of the dashed line that represents stoichiometric conditions, the flame speed increases relatively sharply with an increase in aluminum concentration.

Figure 12 shows the measured flame speeds as a function of aluminum concentration in argon-oxygen mixtures at three different oxygen concentrations of 15,20 , and $30 \%$. As can be seen, in fuel-lean mixtures the flame speed increases linearly with aluminum concentration, within the scatter, but is relatively insensitive to the oxygen concentration in the mixture. At all oxygen concentrations, the flame speed reaches an approximate plateau level in rich mixtures, and the average plateau value is larger for mixtures with larger oxygen content. This demonstrates a relatively strong dependence of the flame speed on oxygen concentration for fuel-rich mixtures. 
The dependence of the flame speed on aluminum concentration in $15 \%$ oxygen mixtures with different gaseous inert diluents $\left(\mathrm{N}_{2}, \mathrm{Ar}, \mathrm{He}\right)$ is shown in Fig. 13. At equal aluminum concentrations, the lowest flame speed is observed in oxygen-nitrogen mixtures followed by slightly higher speeds in mixtures with argon. In contrast, helium increases the flame speed more than three times in comparison to argon-diluted mixtures. The flame speeds are observed to be quite insensitive to the concentration of aluminum for rich mixtures, as observed previously [16].

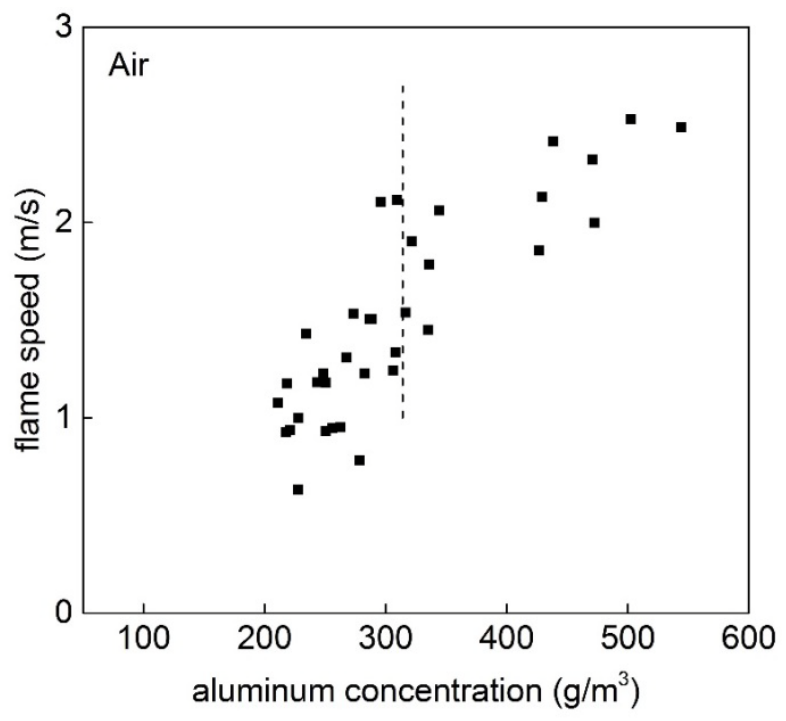

Figure 11. Flame speed at different aluminum concentrations in air for stable flames. 


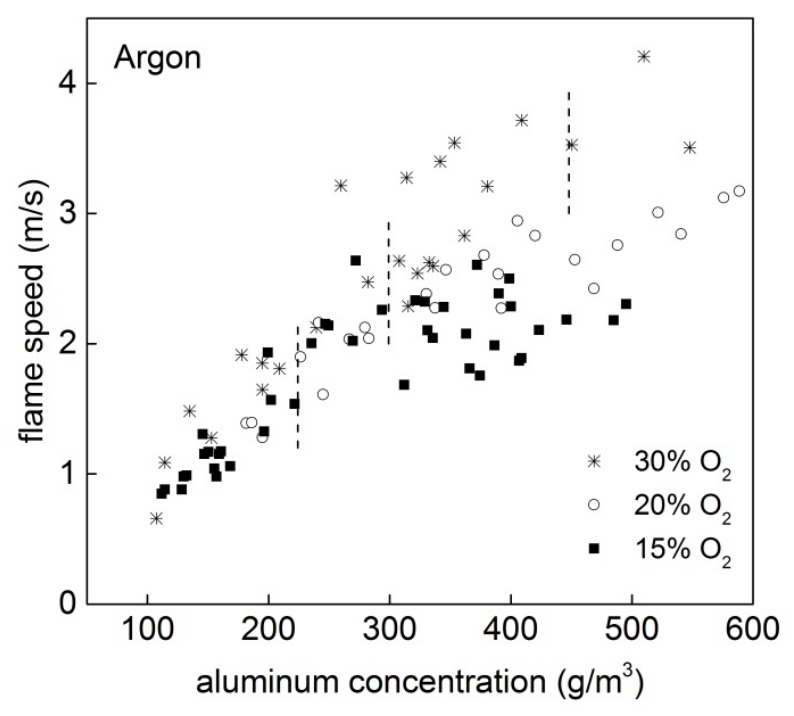

Figure 12. Flame speed versus aluminum concentration in argon mixtures with different oxygen content for stable flames.

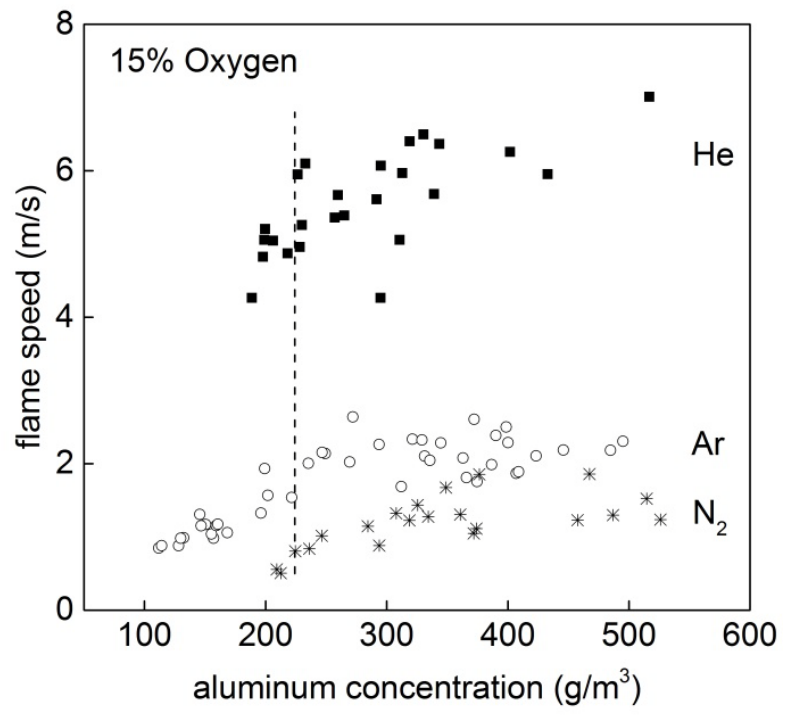

Figure 13. Flame speed versus aluminum concentration in $15 \% \mathrm{O}_{2}$ and $85 \% \mathrm{~N}_{2}$, Ar or He for stable flames.

\subsubsection{Pulsation frequency and average flame speed of pulsating flames}

The flame front in the pulsating regime is also tracked by fitting an ellipse to the front on the images, and the radius is taken to be the average distance between the center of mass and the edge of the ellipse. Figure 14 shows an example of the flame radius tracked as a function of time for a pulsating flame. It can be seen that for very brief periods of time, the flame propagates at extremely high speeds separated by a longer phase where the flame radius effectively does not 
change with time. The average flame propagation speeds of the pulsating flames, obtained from a linear fit to the data, are shown in Fig 15 for three different inert gas diluents with an oxygen concentration of $60 \%$. The results demonstrate that the average flame propagation speed in the pulsating regime increases only with aluminum concentration and, surprisingly, is largely independent of the heat and mass diffusivity of the mixture, which differs by a factor slightly larger than two between helium and argon mixtures. This behavior is strikingly different from a stable flame propagation regime, where the flame speed strongly depends on the thermal diffusivity of the mixture increasing by almost factor of four when argon in mixture with oxygen is replaced by helium (Fig. 13) for flames in 15\% oxygen.

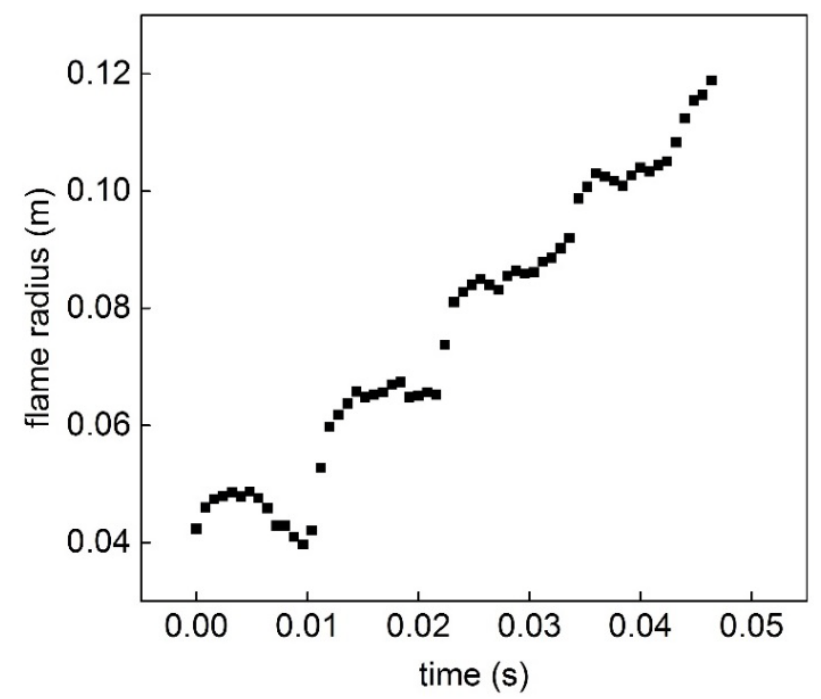

Figure 14. Time dependence of the radius of the pulsating flame in $60 \% \mathrm{O}_{2}$ and $40 \%$ Ar with an aluminum concentration around $280 \mathrm{~g} / \mathrm{m}^{3}$. 


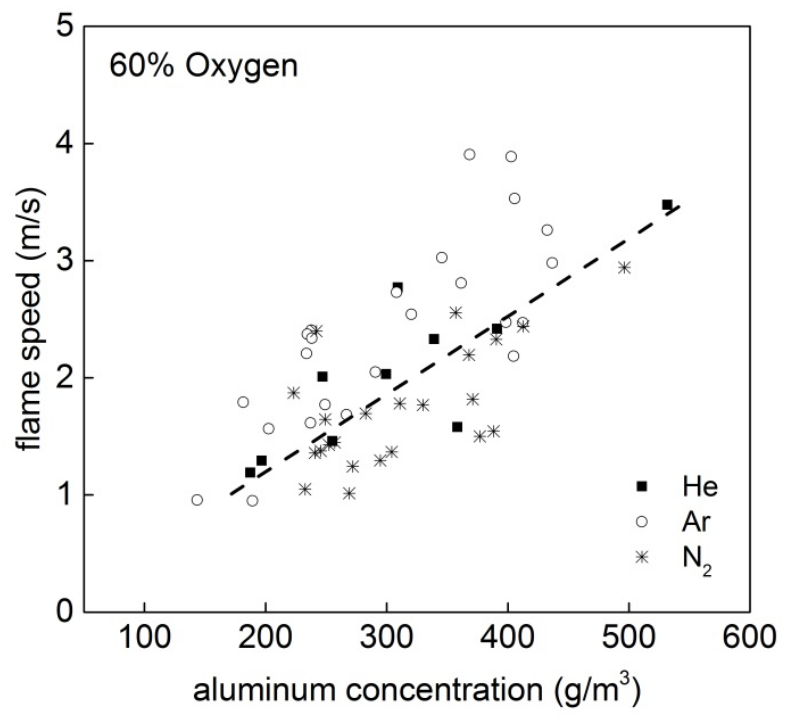

Figure 15. Average propagation velocity of the pulsating flame versus aluminum concentration in $60 \% \mathrm{O}_{2}$ and $40 \% \mathrm{~N}_{2}$, Ar or He.

A typical variation of the pulsating flame brightness recorded by the photodiode is shown in Fig. 16, superimposed with the acoustic pressure signal recorded by the microphone. It is evident that both traces coincide in frequency and are in-phase, indicating that acoustic pulsations are induced by the pulsating flame. Figure 17 presents an example of the light emitted from a flame with decaying pulsations undergoing transition from the pulsating mode to a stable flame propagation mode.

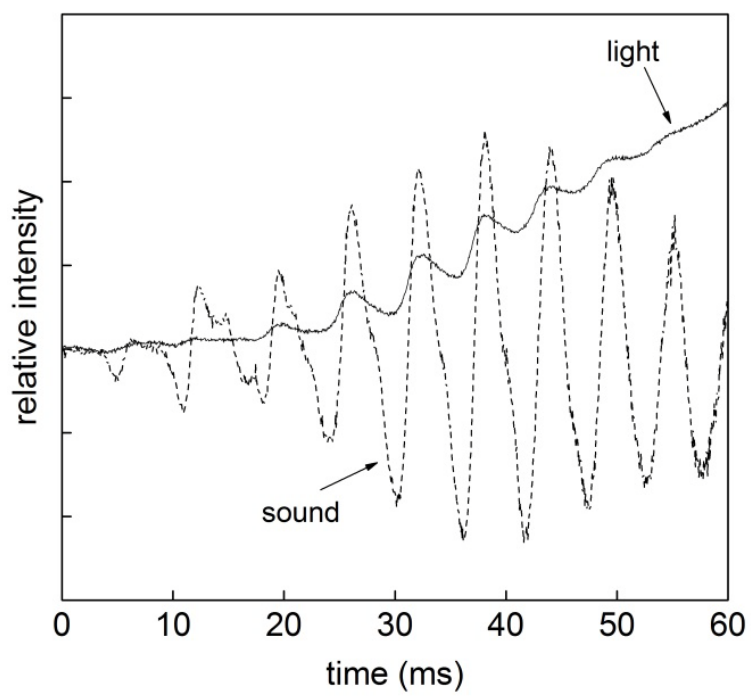

Figure 16. Typical light and sound pressure signals from pulsating flame $\left(60 \% \mathrm{O}_{2}\right.$ and $40 \%$ Ar mixture, aluminum concentration around $420 \mathrm{~g} / \mathrm{m}^{3}$ ). 


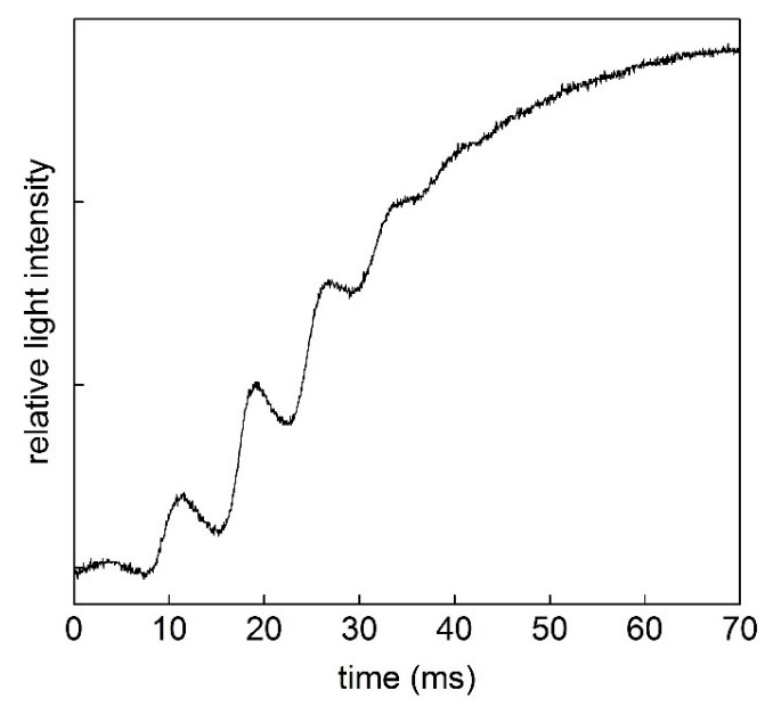

Figure 17. Typical light signal from a flame with decaying pulsations $\left(42 \% \mathrm{O}_{2}\right.$ and $58 \%$ Ar mixture, aluminum concentration about $450 \mathrm{~g} / \mathrm{m}^{3}$ ).

Figure 18 illustrates the dependence of the frequency of flame oscillations on the aluminum concentration in fuel-lean mixtures of $80 \%$ oxygen diluted with either argon or helium. The dependence of the flame oscillation frequency on aluminum concentration under different concentrations of oxygen in argon-oxygen mixtures is illustrated in Fig. 19 for $42 \%$, $60 \%$, and $80 \%$ oxygen. As can be seen, in both cases, the frequency increases approximately linearly with aluminum concentration, while neither the oxygen concentration nor the type of inert gas exhibit any substantial influence on the oscillation frequency. Pulsation frequencies do not noticeably change in helium mixtures, which have much higher sound speed. Furthermore, experiments were performed for different balloon sizes, enclosure sizes and balloon thicknesses and yielded the same frequency for a given aluminum concentration. 


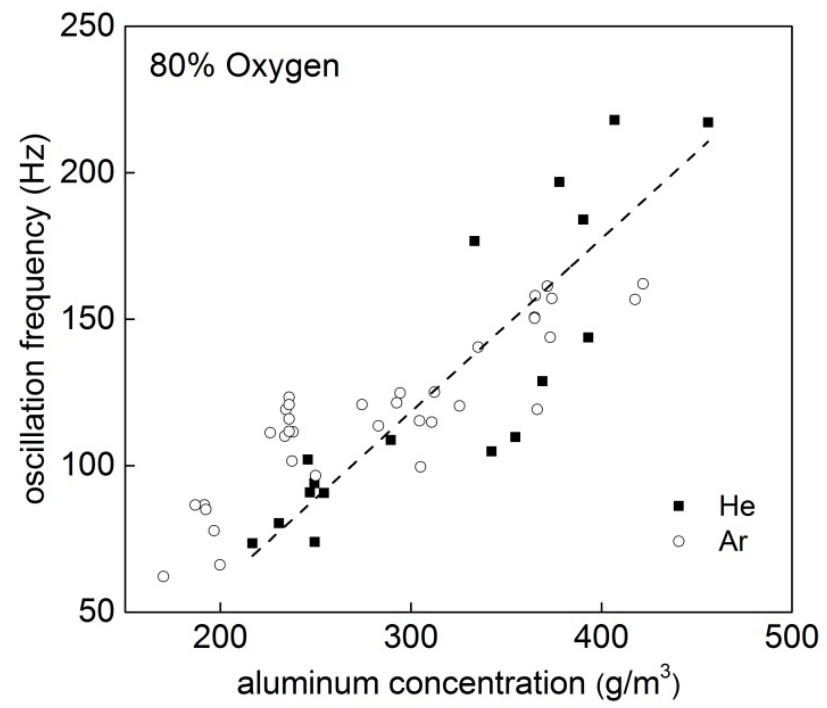

Figure 18. Dependence of the flame pulsation frequency on aluminum concentration in $80 \% \mathrm{O}_{2}$ and $20 \% \mathrm{Ar}$ or He

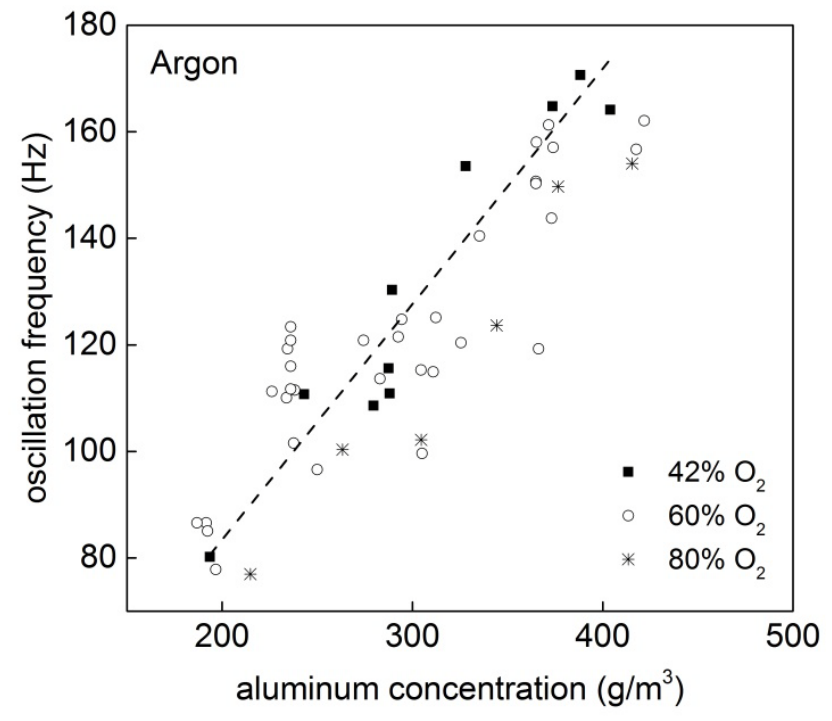

Figure 19. Dependence of the flame pulsation frequency on aluminum concentration in $\mathrm{O}_{2}$-Ar mixtures with varying $\mathrm{O}_{2}$ concentrations of $42 \%, 60 \%$ and $80 \%$. 


\subsection{Large-scale experiments}

\subsubsection{Flame propagation speeds}

In total, 18 suscessful trials were performed using the experimental set-up described in section 2.2. Selected still frames from high-speed movies of the flame propagation event through the dust cloud are shown in Fig. 20. The top row shows images of the flame initiated with zero ignition delay time after dispersion. The bottom row shows a flame propagation event initiated with a 0.4 second delay following the end of the dust dispersion process. Because the cloud continues to move upwards after the powder dispersal stops, the position of the ignition charge for the longest ignition delays is raised to $1 \mathrm{~m}$ above the dispersion nozzle, while, for zero-delay ignition, the igniter was positioned next to the dispersion nozzle exit. Attempts to increase the ignition delay time beyond 0.4 seconds were unsuccessful as the flame either did not propagate through the whole length of the cloud or was increasingly asymmetrical, indicating the development of strong fuel concentration gradients. The average aluminum concentration in the cloud is estimated by dividing the mass of the dispersed powder by the volume of the cloud at the end of dispersal process, derived from video images, and is found to be close to stoichiometric conditions for all large-scale tests.
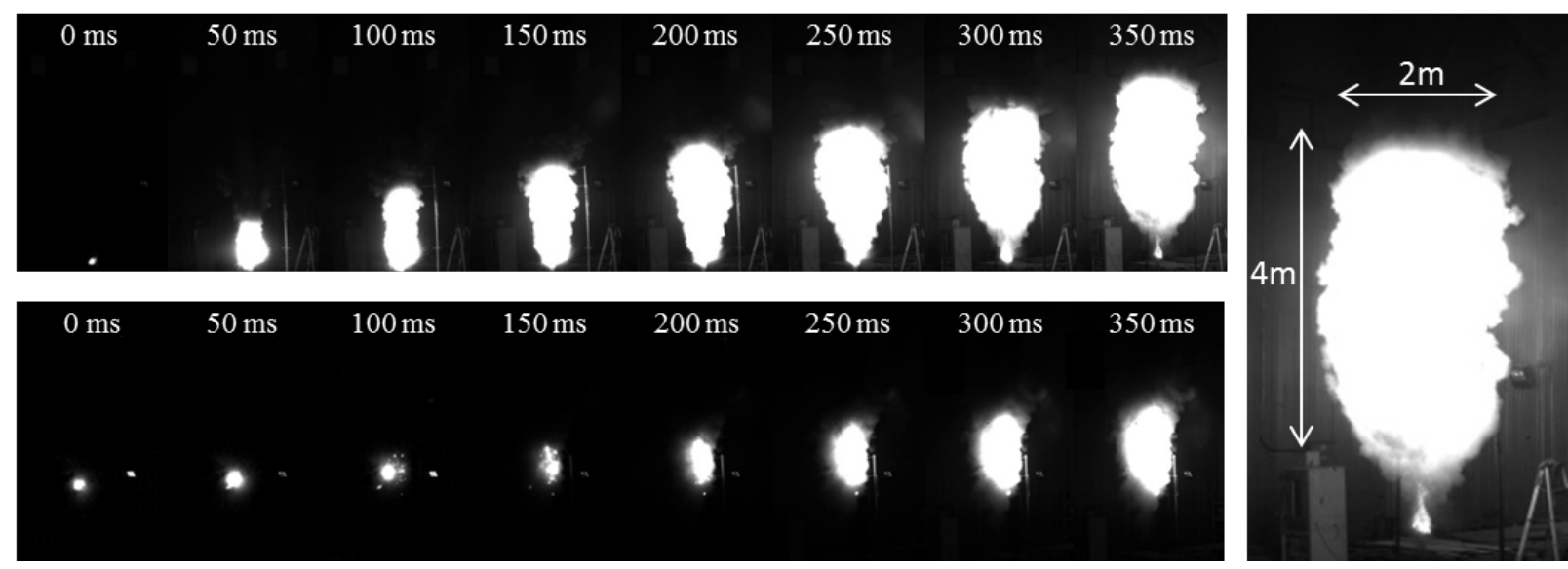

Figure 20. Still frames of flames ignited without delay (top) and with 0.4 seconds delay (bottom) after the end of the dust dispersion process for Valimet $\mathrm{H}-5$ powder and a concentration around stoichiometry.

The procedure for obtaining the flame propagation speed from the high-speed movies is described in detail in [23] and is based on tracking and averaging the flame movement through individual columns of vertical pixels of the images. Some fraction of the observed flame propagation velocity is induced by the buoyancy forces lifting the combustion products upwards. The buoyancy-induced flame speed is estimated by tracking the upward movement of the combustion products after the flame reaches the top of the cloud, which was found to be in the range of $2.5 \pm 1 \mathrm{~m} / \mathrm{s}$. The average flame speed values measured in $\mathrm{H}-5$ and $\mathrm{H}-10$ aluminum dust clouds at different ignition delay times, reduced by the speed induced by buoyancy, are 
shown in Fig. 21. The error bars are the sum of the standard deviations of the flame measurements and the buoyancy-induced speeds. As in the balloon experiments [23], the flame propagation in large dust clouds is strongly influenced by the initial turbulence induced by the dust dispersal process. However, as can be seen from Fig. 21, the influence of turbulence is significantly reduced with a delay time between the end of the powder dispersal and the ignition event of 0.3-0.4 seconds.

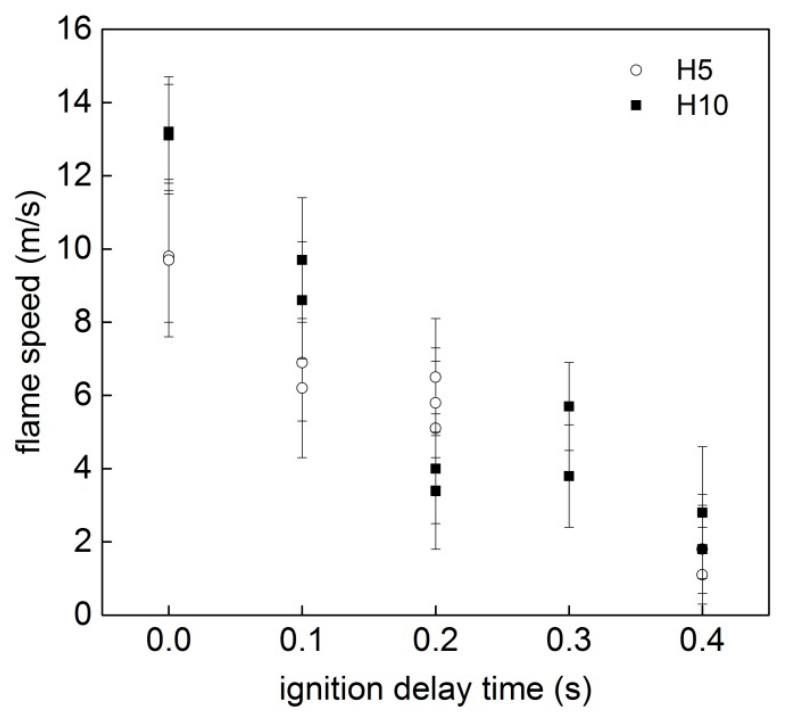

Figure 21. Flame speed as a function of mixture ignition delay time in dust clouds of $\mathbf{H}-5$ and $\mathbf{H}-10$ Valimet aluminum powders for aluminum concentrations around stoichiometry.

\subsubsection{Mixture pre-heating by radiation}

A typical result illustrating the temperature history in the dust cloud prior to the arrival of the flame front, recorded by the array of three thermocouples of different sizes, is shown in Fig. 22. Starting from the bottom curve to the top, the three temperature traces represent the output signals from thermocouples with junction diameters of $0.25,0.125$ and $0.075 \mathrm{~mm}$, respectively. The top temperature trace is derived by extrapolating the temperature signals from thermocouples at each moment in time to the signal that would be produced by a "zero-sized junction" thermocouple with no thermal inertia, indicative of the gas-phase temperature. The two different slopes of the gas temperature curve indicate preheating of the reactants by the absorbed radiative flux emitted by the flame and the combustion products, followed by the rapid heating via molecular heat diffusion with the arrival of the flame front. The maximum temperature attained by the mixture due to radiative heating is indicated in Fig. 22 by a dashed line and was below $200{ }^{\circ} \mathrm{C}$ in all experiments. The test facility was not heated and, therefore, the initial temperature of $0{ }^{\circ} \mathrm{C}$ corresponds to the room temperature during the tests. 


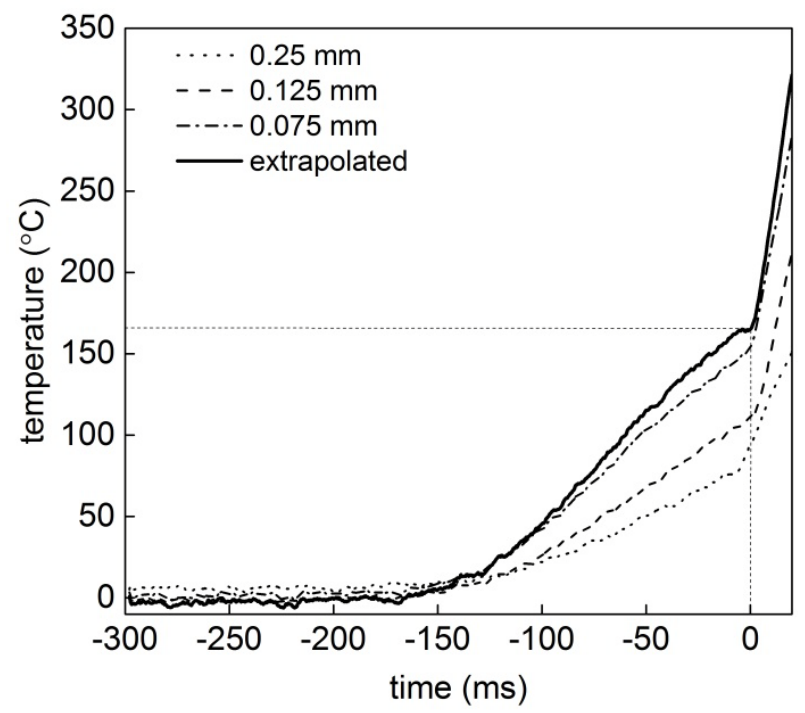

Figure 22 Temperature traces as a function of time for different size thermocouples ahead of the flame front (dashed lines). The solid line represents signal extrapolation to "zero-size" thermocouple. Powder H-5, 0.3 sec ignition delay time and an aluminum concentration around stoichiometry.

\section{Discussion}

Detailed modeling and quantitative numerical analysis must be performed to explain the various physical phenomena observed in the present work and will be the subject of a subsequent publication. However, some qualitative explanations of the observed phenomena and trends based on physical considerations can be discussed. The flame speed dependence on dust cloud parameters in the stable flame-propagation regime are interpreted using some of our previouslypublished qualitative dust-flame models. The physical interpretation of the observed unstable combustion regimes is based upon thermo-diffusive instability theory developed for the description of similar phenomena for gaseous and condensed-phase mixtures. Large-scale tests are interpreted using a basic hydrodynamic model to obtain the burning velocity, and the effect of radiation is discussed in the context of pre-heating of reactants.

\subsection{Stable flame propagation}

\subsubsection{Flame speed and burning velocity}

Similarly to flames in gas mixtures, the burning velocity of a spherically-propagating, constant-pressure dust flame can be found by simply dividing the measured flame speed by the expansion coefficient, defined as the ratio of the density of unburned mixture to the density of combustion products [29]. For any given aluminum concentration, this ratio can be calculated using an equilibrium code, such as Chemical Equilibrium with Applications (CEA) developed by NASA [30], that calculates both equilibrium temperatures and the number of moles of gaseous 
combustion products. The burning velocities derived from the balloon experiments for mixtures in $20 \%$ oxygen diluted with argon are shown in Fig. 23 in comparison to the data obtained previously from experiments with Bunsen dust flames for the same batch of Ampal-637 aluminum powder [16] in argon and $21 \%$ oxygen. As can be seen from Fig. 23, the burning velocities obtained from the two different experiments are in agreement, as was shown for aluminum-air flames in a previous publication [24]. The agreement between two different experimental methods with different geometries implies that the notion of burning velocity as a fundament physical-chemical parameter also applies for flames in metal suspensions, similar to gas flames.

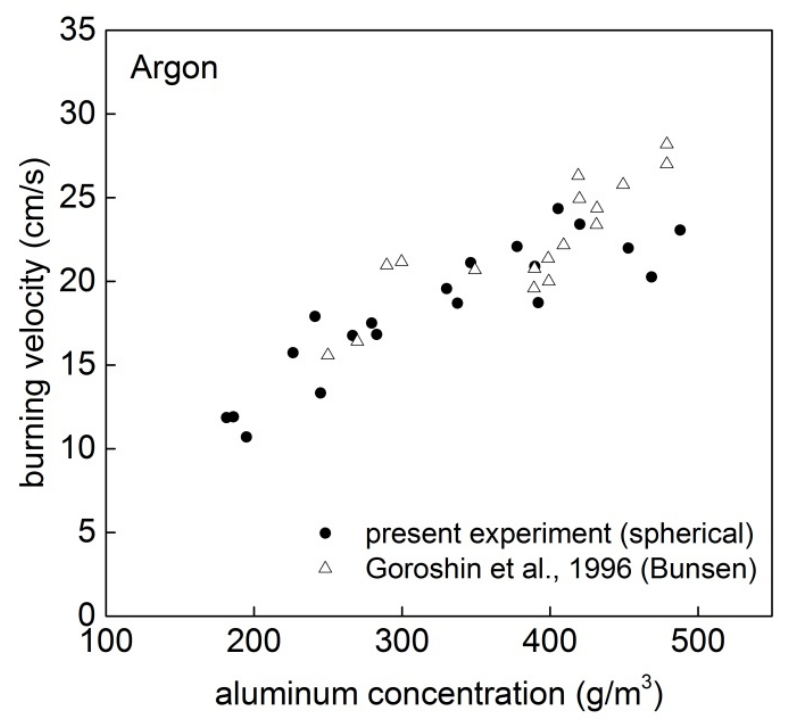

Figure 23. Comparison of the burning velocities derived from balloon experiments and Bunsen-type dust flames [16] in argon mixed with $20 \% \mathrm{O}_{2}$ for balloons and $21 \% \mathrm{O}_{2}$ for Bunsen flame.

\subsubsection{Dependence of the burning velocity on aluminum and oxygen concentration}

The effect of aluminum concentration on the flame burning velocity at different levels of oxygen concentration is illustrated in Fig. 24 with argon being the inert diluent. Again, the burning velocities are obtained from the data of Fig. 12 by multiplying the flame speed by the expansion coefficient, which is also obtained with an equilibrium solver. The solid lines shown represent the trends of the flame speeds for the three different oxygen concentrations. 


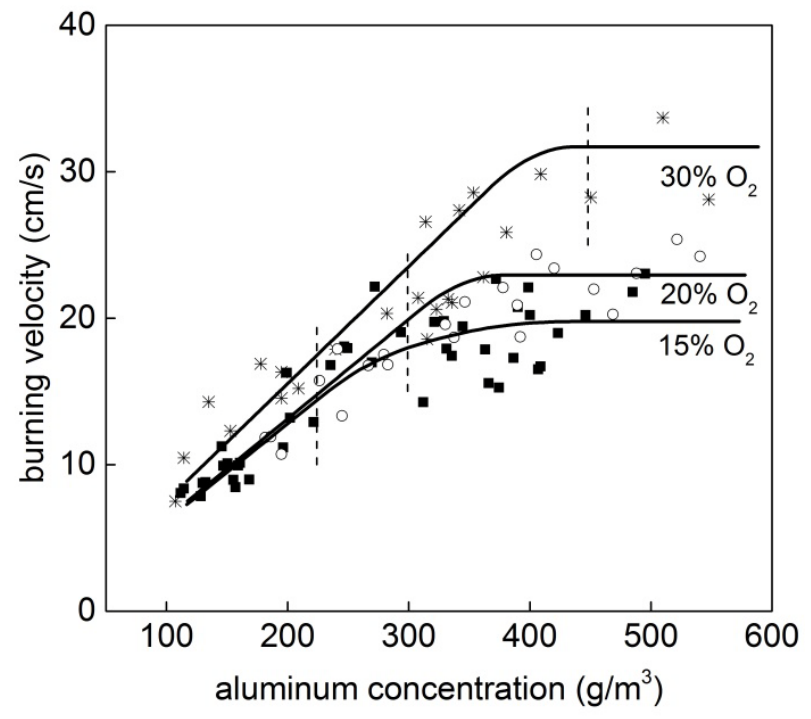

Figure 24. Dependence of burning velocity in aluminum suspensions on fuel concentration at different concentrations of oxygen diluted with argon.

As evident from Fig. 24, the dependence of the burning velocity with increasing aluminum concentration demonstrates the same qualitative behavior at all oxygen concentrations. The flame velocity increases with aluminum concentration in lean mixtures and then plateaus after crossing the stoichiometric value exhibiting very low sensitivity to dust concentration in fuel-rich mixtures. This behavior is different to flames in gaseous fuel mixtures where the dependence of the flame speed on the fuel equivalence ratio is more or less symmetrical around the stoichiometric value. There are two major reasons for this distinctive feature of dust flames. First of all, the flame temperature decreases less significantly with an increase of the fuel concentration in fuel-rich solid suspensions than in gases. This is because an increase in solid-fuel concentration only increases the specific heat of the mixture without diluting the oxygen concentration, since the solid particles occupy a negligible volume. Thus, the calorific value of a rich dust mixture is defined solely by the oxygen concentration and not the fuel. The second reason is that the rate of aluminum particle combustion in the diffusivecombustion regime is not very sensitive to the reduction in bulk flame temperature, due to the formation of micro-diffusion flames around each particle with each flame temperature at the stoichiometric value. In fact, a larger reaction surface area in rich mixtures actually leads to a faster reaction rate, compensating for the decrease in flame temperature and, thus, keeping the value of flame speed relatively constant.

As can be seen from Fig. 24, the seemingly weak dependence of the burning velocity on oxygen concentration in fuel-lean mixtures is the most striking result observed in the present study for stable flames in aluminum suspensions. Regardless of the aluminum particle combustion regime, i.e., kinetic- or diffusion-limited, the particle reaction rate is proportional to the oxygen concentration. In accordance with the basic theory of diffusion-reaction waves in a 
reacting continuum [31], the propagation speed of the front is proportional to the square root of the reaction rate, which is equivalent to the square root of the oxygen concentration. The only reasonable explanation for the observed flame reduced sensitivity to oxygen concentration is the recently-developed theory of discrete flame propagation [32]-[34]. This theory predicts that in a system with fast-reacting, spatially-discrete heat sources, inter-source heat diffusion controls the flame propagation rate, resulting in a decrease in sensitivity of the flame speed on reaction time of the particles with oxygen. Based on this theory, the estimations provided in a previous publication [35] have actually predicted the results experimentally observed here. As the concentration of aluminum increases, the inter-particle spacing decreases and the discrete flame effects diminish. In fuel-rich mixtures, the amount of burned aluminum also rises proportionally to the oxygen content resulting in higher flame temperatures and, correspondingly, higher flame speeds for higher oxygen concentrations.

\subsubsection{Effect of the gas molecular transport coefficients on the burning velocity}

As in gaseous flames, the burning velocity in solid suspensions is roughly proportional to the square root of the heat diffusivity of the gas multiplied by the reaction rate. In addition, the rate of particle combustion in the diffusive combustion regime is proportional to the diffusivity of oxygen towards the micro-flames surrounding each particle. Combining these two factors gives the expression $S_{L, \mathrm{He}} / S_{L, \mathrm{Ar}}=\sqrt{(\alpha D)_{H e} /(\alpha D)_{A r}}$ for the dependence of the burning velocity, $S_{L}$, in terms of the heat diffusivity $\alpha$ and mass diffusivity of oxygen $D$ for helium and argon as inert gases (they have equivalent heat capacities) [16]. This predicts a 3.9 fold flame speed increase for mixtures in 15\% oxygen. As can be seen from the flame speed data in Fig 13, the ratio between the flame speeds in argon and helium is around 2.9. Perhaps this discrepancy could be explained by uncertainty in the measured values; however, a lower experimental ratio of burning velocities in helium-oxygen and argon-oxygen mixtures was also observed in experiments with stabilized aluminum Bunsen dust flames [16]. This trend of discrepancies points towards a different mode of particle combustion depending on whether oxygen is diluted with argon or helium. Particle combustion in argon mixtures is controlled by the diffusion of oxygen towards the diffusion micro-flame surrounding each particle and the experimental evidence indicates that a heterogeneous kinetically-controlled reaction at the surface might be the limiting reaction stage in helium mixtures due to their higher molecular heat and mass transfer coefficients [21]. In the asymptotic case of kinetically-controlled combustion, the flame speed depends on heat diffusivity only. Any intermediate (partial) dependence on oxygen diffusivity would indicate a transient particle combustion regime [36]. 


\subsubsection{Effect of cloud geometry and radiation heat transfer on the burning velocity in large- scale aluminum dust clouds}

In order to derive the burning velocity from the flame speed measured in the present large-scale experiments, one has to account for the specific geometry of the axial flame in a cylindrical cloud. After combustion, the gas expands due to the increase in temperature and the change of mean molecular weight. Depending on the geometry, this expansion effectively acts as a piston displacing the reactants and surrounding air so that the flame moves faster in the laboratory frame than the fundamental burning velocity. In the case of a spherical flame with central ignition, as in the balloon experiments, the combustion products are self-confined, and the burning velocity is obtained by multiplying the flame speed by the ratio of the densities of the burnt and unburnt mixtures. For clouds with an approximately cylindrical geometry, as in the present field experiments, the effect of gas expansion is different. Feng et al. [37] and later Kaptein and Hermance [38] developed an analytical model to calculate the expansion coefficient for flames propagating in methane-air layers within underground mine galleries. By extending their analysis to the present axi-symmetrical and practically unconfined conditions, the model predicts that the observed flame speed is related to the burning velocity by the expression $S_{b}=S_{f} \sqrt{\rho_{b} / \rho_{u}}$. The burning velocity, calculated using this expression from the flame speed data with a maximum ignition delay time of $0.4 \mathrm{~s}$, is in the range of about $45 \pm 10 \mathrm{~cm} / \mathrm{s}$, which is more than twice the flame burning velocity of about $20 \mathrm{~cm} / \mathrm{s}$ from the experiments with smallscale laboratory Bunsen flames [16] and flames in balloons [24].

Unlike combustible gas mixtures that are largely transparent to radiation, suspensions of solid fuel particles can efficiently absorb the thermal radiation emitted by the flame and the combustion products [39]. In dust flames, radiation goes from being a source of heat loss to a mechanism of heat transfer from the flame and combustion product to the unburned fuel mixture. Numerous theoretical models of flames that include radiation heat transfer in suspensions of various solid fuels, or even gas fuels laden with inert particles, have predicted radiation to be an important, or even dominant, flame propagation mechanism capable of increasing the flame speed by more than an order of magnitude in comparison to flames driven by molecular heat conductivity alone [40]-[43]. In practice, however, no noticeable effects of radiation have been observed during laboratory testing of dust suspensions, including the present experiments in latex balloons, suggesting that the scale of the laboratory flames is insufficient for efficient absorption of the radiative heat flux. The mean free path of a photon in a stoichiometric aluminum cloud can be estimated to be on the order of $4-5 \mathrm{~cm}$. However, most of this radiation is scattered and not absorbed by the particles. The estimated absorption cross-section of a micronsize aluminum particle in the 2-5 micron wavelength region, characteristic of aluminum flame thermal radiation, is below 0.1 [44]. Correspondingly, the absorption length of radiation in an aluminum cloud is at least an order of magnitude greater than the mean free path of photons. Indeed, as can be seen from the thermocouple traces in Fig. 22, in a large dust cloud, the 
suspension starts to be heated by radiation $150 \mathrm{~ms}$ prior to the flame arrival. With a flame propagation speed in this case of about $5 \mathrm{~m} / \mathrm{s}$, this time corresponds to a distance of about 50-100 $\mathrm{cm}$, larger than the scale of a flame propagating through a balloon of $30 \mathrm{~cm}$ diameter and much larger than the Bunsen flame which has a characteristic dimension of $1-2 \mathrm{~cm}$.

The effect of the initial temperature on the burning velocity in aluminum suspensions was previously measured by Goroshin et al. [39] and a 2-fold increase was observed for the $170 \mathrm{~K}$ increase in initial temperature shown on Fig. 22. Using an initial value of about $20 \mathrm{~cm} / \mathrm{s}$, the burning velocity of a flame propagating through a cloud of aluminum powder at $440 \mathrm{~K}$ would be on the order of $40 \mathrm{~cm} / \mathrm{s}$, which is comparable to the value obtained from the present field experiments once the expansion coefficient and buoyancy-induced velocity are taken into consideration.

\subsubsection{Unstable flames}

Contrary to acoustic oscillations previously observed in tubes [45], [46], pulsations in balloons are observed only in fuel-lean mixtures and are the strongest near the lean flame propagation limit indicating that their physical nature is very different from acoustic coupling. Similar pulsating flames in fuel suspensions have only been observed and reported once, for flames in suspensions of large PMMA particles in microgravity [47], [48]. Those authors considered the pulsations to be caused by periodical preheating of the fresh mixture by flame radiation. This, however, is an unlikely explanation since, as was discussed above, radiation cannot be sufficiently absorbed by the unburned mixture in small-scale dust clouds and primarily acts as a heat-loss mechanism. The effects of radiative heat transfer should also increase with fuel concentration, whereas pulsating flames are observed only in fuel-lean mixtures and are replaced by stable flame propagation when the fuel concentration approaches stoichiometric conditions. Thus, the observed pulsating and other unstable flame-propagation regimes are most probably the manifestation of thermo-diffusive instabilities, characteristic of flames with Lewis numbers deviating from unity [27], [49], [50].

Near stoichiometric concentrations, the diffusion of heat through the flame in the suspension is balanced by the diffusion of oxygen, resulting in Le numbers close to unity and steady flame propagation [51], [52]. According to flame stability theory, thermo-diffusive instabilities appear when this balance is broken, i.e., when the diffusion of either heat or mass begins to dominate over the other. For fuel-rich dust suspensions, the Lewis number is smaller than unity, which results in a cellular structure of the flame front [52]. Cellular flames have been observed in fuel-rich iron dust mixtures of small iron particle sizes during microgravity experiments by Tang et al. [20] as well as in the present balloon experiments when the aluminum concentration is above $500 \mathrm{~g} / \mathrm{m}^{3}$. Increasing the dust concentration beyond the stoichiometric value does not change the heat conductivity of the mixture because the particles occupy a negligibly small volume. However, the heat diffusivity of the mixture does decrease with an increase in powder concentration due to the increase in heat capacity and density of the overall 
suspension. This effect yields Lewis numbers below unity for fuel-rich mixtures, causing the formation of cellular flames.

For fuel-lean dust mixtures, the gradient of oxygen concentration across the flame is small and the diffusion of oxygen does not substantially affect the flame structure. The Lewis number becomes very large due to the zero diffusivity of metal particles in suspension, and a different type of instability arises. These instabilities take the form of pulsations, target patterns, or spiral waves, and have been observed in numerous systems that support reaction-diffusion waves [53]-[55]. For combustion systems, the criterion for the onset of pulsating instabilities has been established by Joulin and Clavin and can be written as follows: $\beta(L e-1)>16$, with $\beta$ being the Zeldovich number [42]. In other words, pulsating and spiral-wave instabilities are possible only for systems with sufficiently large Lewis numbers, high activation energy and low flame temperatures. These types of instabilities have been mostly observed in condensed systems [56]-[59] and rarely for gaseous flames due to the difficulty in creating combustible gaseous mixtures satisfying the instability criterion [28], [60]-[62].

A qualitative map of the different flame propagation regimes observed in the present experiments for aluminum suspensions as a function of the oxygen and aluminum concentrations is shown in Fig. 25.

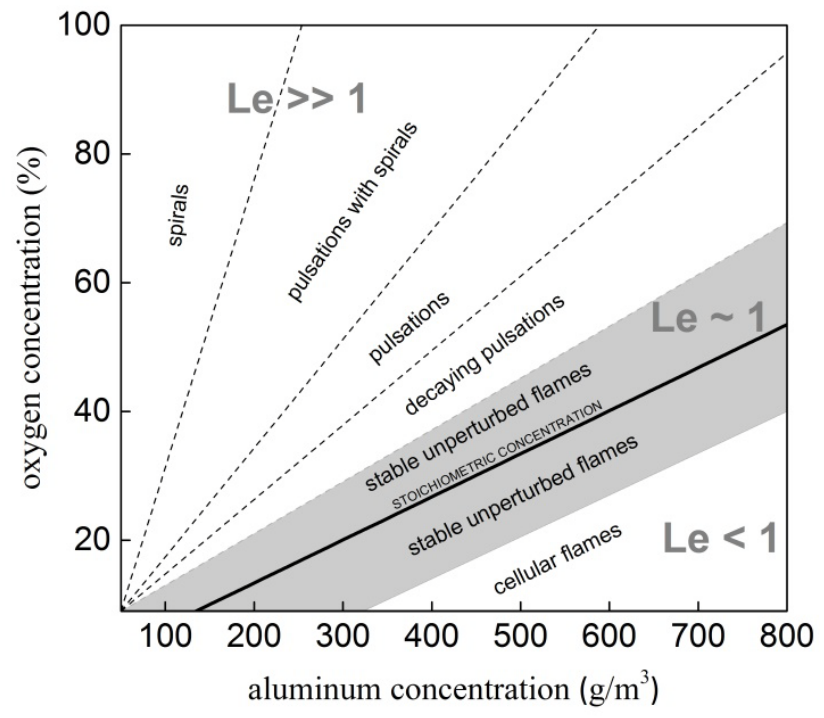

Figure 25. Map of the flame propagation regimes within fuel-oxygen concentration coordinates

As can be seen from Fig. 25, the structure of the map of the flame propagation regimes generally follows the criteria for stable/unstable flame propagation predicted by flame thermodiffusive instability theory. However, a number of the phenomena observed in the present work 
still lack a clear physical explanation. For example, the flame trajectories in the pulsating regime shown in Fig. 14 indicate that brief periods of rapid flame movement are followed by comparatively-long periods of flame stagnation. The behavior within this flame propagation regime is difficult to rationalize with laminar flame theory. Also, the independence of the average flame propagation speed on the heat diffusivity of the gas mixture observed for pulsating flames and presented in Fig. 18 also seemingly contradicts the very nature of a flame driven by molecular heat diffusivity. One possible explanation may be that the observed pulsating phenomenon is closer to a series of consecutive thermal explosions, as described by the nonstationary thermal explosion theory developed first by Frank-Kamenetskii [63]. Each explosion

is followed by a period of thermal relaxation, where the mixture burning rate falls effectively to zero. The combustion products after the explosion act like a hot wall, at a temperature close to the adiabatic value, that heats the reactants in the adjacent layer of the mixture until another thermal explosion event occurs inside the layer of unburned mixture bordering the combustion products from the previous explosion. Further work will be needed to clarify the physical mechanisms responsible for all of the flame propagation regimes shown in the regime map in Fig. 25.

\section{Conclusion}

The present work reports a large set of experimental data on isobaric, freely-propagating flames in aluminum dust clouds, ranging in scale from tens of centimeters to several meters, that was obtained with two experimental facilities. The main highlights of this experimental work are the following:

- Stable propagation of an unperturbed spherical flame was only observed in the vicinity of the stoichiometric concentration. Pulsating, spiral and combined spiral-pulsating flames were observed in fuel-lean mixtures and the formation of a cellular pattern on the flame front was evident in fuel-rich dust clouds. The appearance of unstable combustion generally follows the predictions of thermo-diffusive flame stability theory corresponding to pulsating flame instabilities at large Le numbers (fuel-lean dust suspensions) and cellular instabilities for Le numbers below unity (fuel-rich clouds).

- For the stable flame propagation regime in fuel-lean mixtures, the flame speed is quite insensitive to the oxygen concentration. For fuel-rich suspensions, the flame speed is insensitive to an increase in aluminum concentration. The first observation can be explained in terms of the discrete flame theory that takes into account inter-particle heat transfer. The latter observation is primarily a consequence of the insensitivity of the particle combustion rate to flame temperature in the diffusive regime.

- The burning velocity derived from flame propagation speeds in balloons correlates well with previously measured values from stabilized aluminum Bunsen flames whereas the value of the burning velocity observed in large-scale dust clouds is larger by almost a factor of two. The increase in burning velocity is attributed to pre-heat of the reactants by radiation emitted from the combustion zone and combustion products, a phenomenon that only occurs when the size of the cloud is sufficiently large for self-absorption of the radiation. 


\section{Acknowledgements}

Support for this work was provided by the Natural Sciences and Engineering Research Council of Canada and Martec, Ltd., under a Collaborative Research and Development Grant, and the Defense Threat Reduction Agency under contract HDTRA1-11-1-0014 (program manager Suhithi Peiris). The authors would like also to acknowledge S. Dorofeev and R. Bauwens for discussions on flame instabilities and the effect of partial confinement, as well as students $\mathrm{C}$. Kowal and J. Hayto for their help in conducting experiments.

\section{References}

[1] K. L. Cashdollar, M. Hertzberg, Introduction to dust explosion, in: K. L. Cashdollar and M. Hertzberg (Eds.) Industrial dust explosion, ASTM 958, 1987, 5-32.

[2] R. Eckhoff, Dust explosions in the process industries: identification, assessment and control of dust hazards. Gulf professional publishing, 2003.

[3] I. Hartmann, J. Nagy, and M. Jacobson, Recent studies on the explosibility of cornstarch. US Dept. of the Interior, Bureau of Mines, 1950.

[4] L. Meda, G. Marra, L. Galfetti, F. Severini, and L. De Luca, Mater. Sci. Eng. C, 27, (2007), 1393-1396.

[5] O. F. Theimer, Powder Technol., 8, (1973), 137-147.

[6] M. Jacobson, A. R. Cooper, and J. Nagy, Explosibility of metal powders, DTIC Document, (1964).

[7] J. H. Burgoyne and L. Cohen, Proc. R. Soc. London. Ser. A. Math. Phys. Sci., 225, (1954), 375-392.

[8] W. Felder and A. Fontijn, J. Chem. Phys., 64, (1976), 1977-1980.

[9] A. Fontijn, W. Felder, and J. J. Houghton, Proc. Combust. Inst., 16, (1977), 871-879.

[10] S. Goroshin, F.-D. Tang, A. J. Higgins, and J. H. S. Lee, Acta Astronaut., 68, (2011), 656666.

[11] H. M. Cassel, Some fundamental aspects of dust flames. US Dept. of the Interior, Bureau of Mines, 1964.

[12] D. R. Ballal, Proc. R. Soc. London. A. Math. Phys. Sci., 385, (1983), 21-51.

[13] J.-H. Sun, R. Dobashi, and T. Hirano, J. Loss Prev. Process Ind., 14, (2001), $463-467$. 
[14] J.-H. Sun, R. Dobashi, and T. Hirano, Combust. Sci. Technol., 150, (2000), 99-114.

[15] J.-H. Sun, R. Dobashi, and T. Hirano, J. Loss Prev. Process Ind., 19, (2006), 769-773.

[16] S. Goroshin, I. Fomenko, and J. H. S. Lee, Proc. Combust. Inst., 26, (1996), 1961-1967.

[17] P. Julien, S. Whiteley, S. Goroshin, M. J. Soo, D. L. Frost, and J. M. Bergthorson, Proc. Combust. Inst., 35, (2015) 2431-2438.

[18] P. Julien, M. Soo, S. Goroshin, D. L. Frost, J. M. Bergthorson, N. Glumac, and F. Zhang, J. Propuls. Power, (2014), 1-8.

[19] M. Soo, P. Julien, S. Goroshin, J. M. Bergthorson, and D. L. Frost, Proc. Combust. Inst., 34, (2013), 2213-2220.

[20] F.-D. Tang, S. Goroshin, A. Higgins, and J. Lee, Proc. Combust. Inst., 32, (2009), 19051912.

[21] F.-D. Tang, S. Goroshin, and A. J. Higgins, Proc. Combust. Inst., 33, (2011), 1975-1982.

[22] S. Goroshin, M. Bidabadi, and J. H. S. Lee, Combust. Flame, 105, (1996), 147-160.

[23] J. Palecka, P. Julien, S. Goroshin, J. M. Bergthorson, D. L. Frost, and A. J. Higgins, Proc. Combust. Inst., 35, (2015), 2463-2470.

[24] P. Julien, J. Vickery, S. Whiteley, A. Wright, S. Goroshin, J. M. Bergthorson, and D. L. Frost, J. Loss Prev. Process Ind. (2014) doi:10.1016/j.jlp.2014.12.022

[25] T. Skjold, K. L. Olsen, and D. Castellanos, J. Loss Prev. Process Ind.,26, (2013), 562-570.

[26] E. W. Christiansen, C. K. Law, and C. J. Sung, Combust. Flame, 124, (2001), 35-49.

[27] B. Matkowsky and G. Sivashinsky, SIAM J. Appl. Math., 35, (1978), 465-478.

[28] G. Jomaas, J. K. Bechtold, and C. K. Law, Proc. Combust. Inst., 31, (2007), 1039-1046.

[29] B. Lewis and G. Von Elbe, Combustion, flames and explosions of gases, Cambridge University Press, 1961.

[30] S. Gordon and B. J. McBride, Computer Program for Calculation of Complex Chemical Equilibrium Compositions and Applications I. Analysis, NASA Reference Publication 1311, 1994.

[31] L. D. Landau and E. M. Lifshitz, Theoretical Physics. Vol. 6. Hydrodynamics, Nauka, Moscow, 1986. 
[32] F.-D. Tang, A. J. Higgins, and S. Goroshin, Combust. Theory Model., 13, (2009), 319341.

[33] S. Goroshin, F.-D. Tang, and A. J. Higgins, Phys. Rev. E, 84, (2011), 27301.

[34] F.-D. Tang, A. J. Higgins, and S. Goroshin, Phys. Rev. E, 85, (2012), 36311.

[35] S. Goroshin, J. H. S. Lee, and Y. Shoshin, Proc. Combust. Inst., 27, (1998), 743-749.

[36] M. Soo, S. Goroshin, J. M. Bergthorson, and D. L. Frost, Propellants, Explos. Pyrotech., (2015), DOI: 10.1002/prep.201400269

[37] C. C. Feng, S. H. Lam, and I. Glassman, Combust. Sci. Technol., 10, (1975), 59-71.

[38] M. Kaptein and C. E. Hermance, Proc. Combust. Inst., 16, (1977), 1295-1306.

[39] S. Goroshin, A.J. Higgins, M. Kamel, Powdered metals as fuel for hypersonic ramjets, in: 37th Joint Propulsion Conference and Exhibit, Salt Lake City, Utah, AIAA Paper 2001-3919, American Institute of Aeronautics and Astronautics, 2001, http://arc.aiaa.org/doi/abs/10.2514/6.2001-3919

[40] G. Joulin and P. Cambray, Combust. Sci. Technol., 52, (1987), 397-412.

[41] G. Joulin and M. Eudier, Proc. Combust. Inst., 22, (1989), 1579-1585.

[42] G. Joulin and P. Clavin, Combust. Flame, 35, (1979), 139-153.

[43] G. Joulin and B. Deshaies, Combust. Sci. Technol., 47, (1986), 299-315.

[44] J. Bartl and M. Baranek, Meas. Sci. Rev., 4, (2004), 31-36.

[45] S. K. Aslanov, V. G. Shevchuk, Y. N. Kostyshin, L. V Boichuk, and S. V Goroshin, Combust. Explos. Shock Waves, 29, (1993), 163-169.

[46] S. V Goroshin, V. G. Shevchuk, and N. D. Ageev, Combust. Explos. Shock Waves, 17, (1981), 595-600.

[47] H. Hanai, H. Kobayashi, and T. Niioka, Proc. Combust. Inst., 28, (2000), 815-822.

[48] H. Hanai, K. Maruta, H. Kobayashi, and T. Niioka, Proc. Combust. Inst., 27, (1998), 2675-2681.

[49] B. Khaikin, A. Filonenko, and S. Khudyaev, Combust. Explos. Shock Waves, 4, (1968), 343-348.

[50] G. I. Sivashinsky, SIAM J. App. Math., 40, (1981), 432-438. 
[51] C. K. Law, Combustion Physics, Cambrige University Press, 2006.

[52] M. Matalon, Annu. Rev. Fluid Mech., 39, (2007), 163-191.

[53] S. Jakubith, H. H. Rotermund, W. Engel, A. Von Oertzen, and G. Ertl, Phys. Rev. Lett., 65, (1990), 3013.

[54] V. Volpert and S. Petrovskii, Phys. Life Rev., 6, (2009), 267-310.

[55] S. B. Margolis, H. G. Kaper, G. K. Leaf, and B. J. Matkowsky, Combust. Sci. Technol, 43, (1985), 127-165.

[56] A. V. Dvoryankin, A. G. Strunina, and A. G. Merzhanov, Combust. Explos. Shock Waves, 18, (1982), 134-139.

[57] A. G. Merzhanov and I. P. Borovinskaya, Combust. Sci. Technol., 10, (1975), 195-201.

[58] Y. M. Maksimov, A. T. Pak, G. B. Lavrenchuk, Y. S. Naiborodenko, and A. G. Merzhanov, Combust. Explos. Shock Waves, 15, (1979), 415-418.

[59] A. Makino, Prog. Energy Combust. Sci., 27, (2001), 1-74.

[60] H. Pearlman, Combust. Flame, 109, (1997), 382-398.

[61] H. G. Pearlman and P. D. Ronney, Phys. Fluids, 6, (1994), 4009-4018.

[62] G. Jomaas and C. K. Law, Phys. Fluids, 22, (2010).

[63] D. A. Frank-Kamenetskii, Diffusion and Heat Transfer in Chemical Kinetics. Springer, 1995. 